\title{
The effect of stage of change education based on the use of pain coping mechanisms in female patients with migraine
}

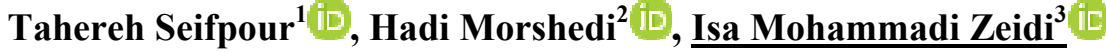 \\ ${ }^{1}$, Student research committee Qazvin University of Medical Sciences, Qazvin, Iran \\ ${ }^{2}$ Social Determinants of Health Research Center, Research Institute for Prevention of Non-Communicable Diseases, Qazvin \\ University of Medical Sciences, Qazvin, Iran \\ ${ }^{3}$ Corresponding author; Social Determinants of Health Research Center, Research Institute for Prevention of Non-Communicable \\ Diseases, Qazvin University of Medical Sciences, Qazvin, Iran \\ Tel:+989124146500_Email: emohammadi@qums.ac.ir
}

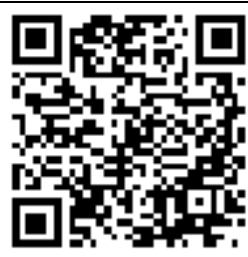

Citation Seifpour T, Morshedi H, Zeidi IM. [Effect of stage matched education on pain coping strategies using in female patients with migraine]. J Birjand Univ Med Sci. 2019; 26(4): 300-14. [Persian]

DOI http://doi.org/10.32592/JBirjandUnivMedSci.2019.26.4.102

Received: 13 February, 2019

Accepted:27 July, 2019

\begin{abstract}
Background and Aim: Along with the effectiveness of the drug therapy, it has been cleared that behavioral interventions and the use of pain coping mechanisms can reduce the consequences of migraine headaches. The purpose of this study was to determine the effect of stage of change education based on the use of pain coping mechanisms in female patients with migraine.

Materials and Methods In this experimental study, with the method multi-stage sampling was performed on 60 female patients with migraine in the experimental and control groups. Data were collected before and 2 months after training by using demographic questionnaire, Chronic Pain Coping strategies questionnaire, Pain self-efficacy scale, Pain stage of change algorithm and Knowledge scale. The experimental group received 5 sessions of 60 -minute group training with targeted educational pamphlet. Data were analyzed by SPSS software (version 23) using chi-square, paired t-test and independent t-test.

Results: The mean incidence, severity, and duration of migraine headaches improved after the intervention in the experimental group $(\mathrm{P}<0.05)$ Moreover, with the exception of the re-evaluation strategy and social support, the mean frequency of all coping strategies increased in experimental group after intervention $(\mathrm{P}<0.05)$. Also, mean score of knowledge and pain self-efficacy was increased in experimental group after intervention $(\mathrm{P}<0.001)$. The rank of the stage of readiness among patients in the experimental group increased after intervention and patients in the experimental group reported active stages of readiness $(\mathrm{P}<0.01)$.

Conclusion: Research findings emphasize the effectiveness of stage of change-based education to improve the use of pain coping management strategies and also, reduction of the frequency, severity, and duration of migraine headaches.
\end{abstract}

Key Words: Migraine; Pain Coping Strategies; Chronic Headaches; Stages of Change; Education; SelfEfficacy. 


\title{
تأثير آموزش مبتنى بر مراحل تغيير بر كاربرد مكانيسمهاى غلبه بر درد در بيماران زن مبتلا به ميكرن
}

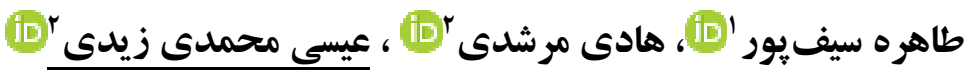

\section{جكيده}

زمينه و هدف: در كنار اثربخشى دارودرمانى، مشخص شده است كه مداخلات رفتارى و كاربرد مكانيسمهاى مقابله با درد منجر به به مانه

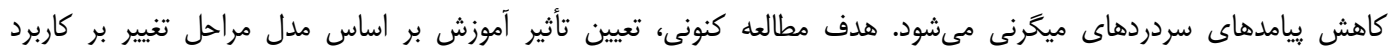

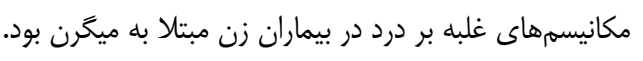

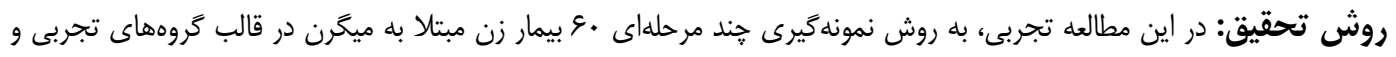

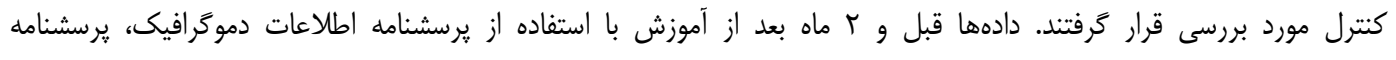

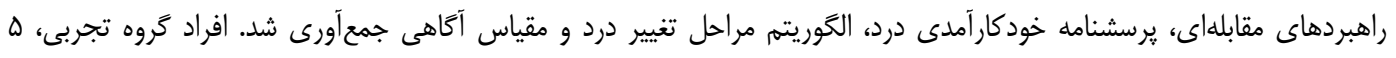

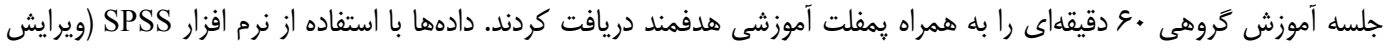

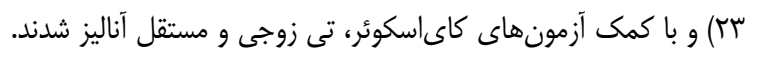

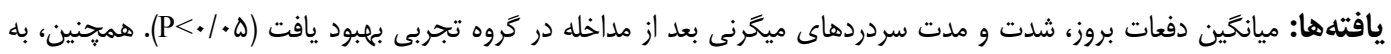

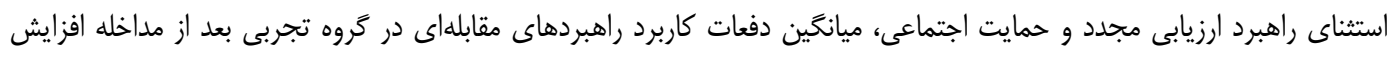

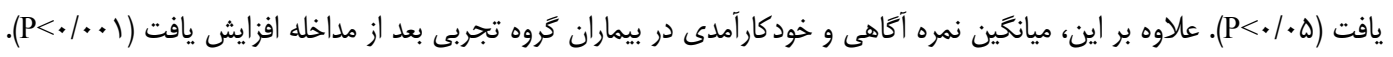

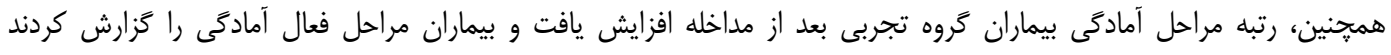

$$
\text { . }(\mathrm{P}<\cdot / \cdot)
$$

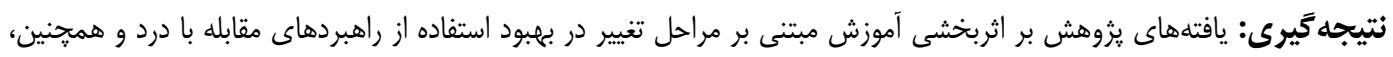
كاهش دفعات، شدت و مدت سردردهاى ميكَرنى تأكيد مى كند.

$$
\begin{aligned}
& \text { وازههاى كليدى: ميكرن، راهبردهاى غلبه بر درد، سردردهاى مزمن، مراحل تغيير، آموزش، خودكار آمدى }
\end{aligned}
$$

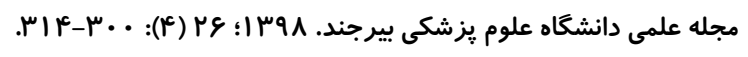

$$
\begin{aligned}
& \text { دريافت: זع/1/ }
\end{aligned}
$$


باعث به وجود آمدن و بلكاركيرى درمانهاى رفتارى معاصر

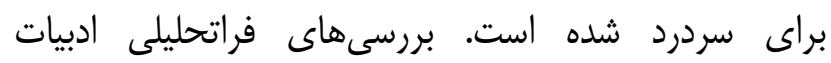

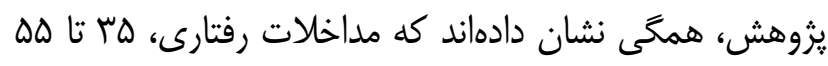

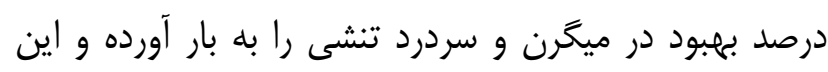

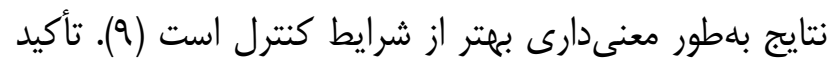

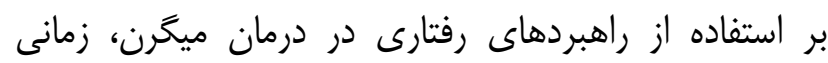

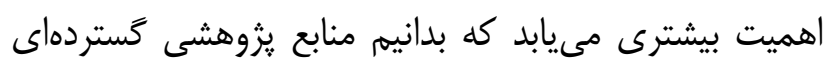

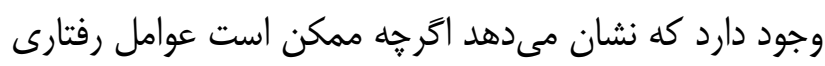

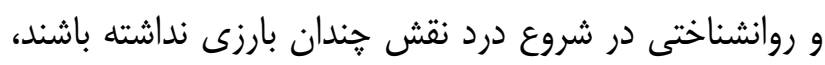

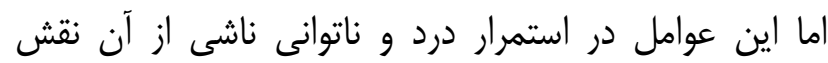
قاطعى ايفا مى كنند (•) (1). يكى از عواملى كه در تجربه روانشناختى و فيزيولوزيك إنى

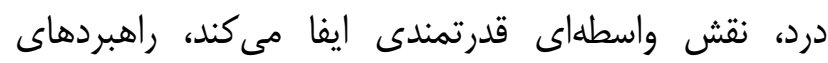

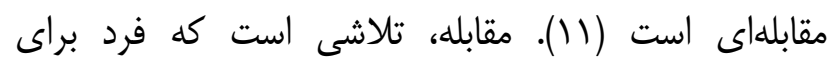

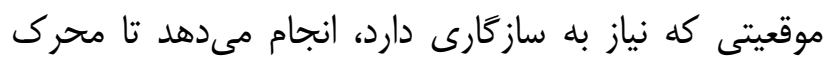

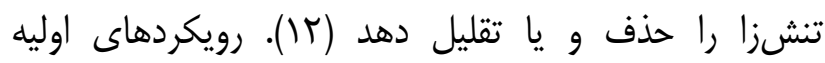

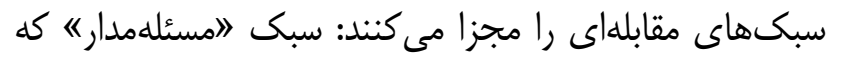

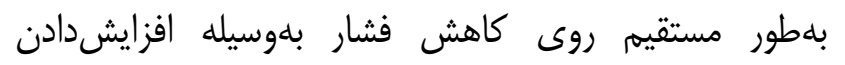

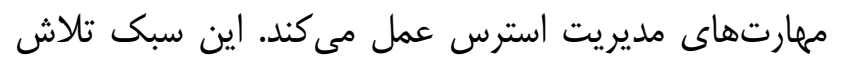

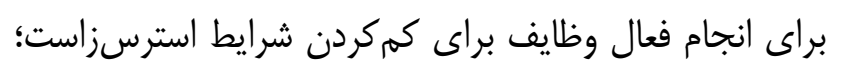

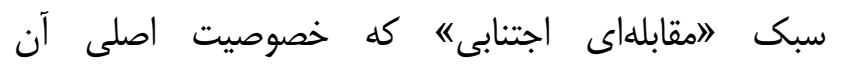

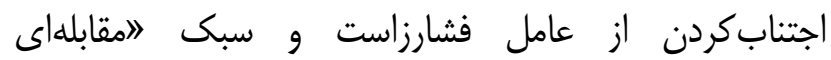
هيجانمدار"، راهبردهاى شناختى براى به تعويق انداختن يا حل عامل استرسزاست (بان)

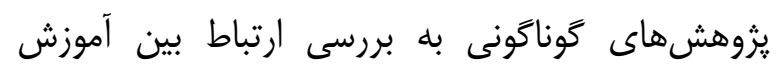

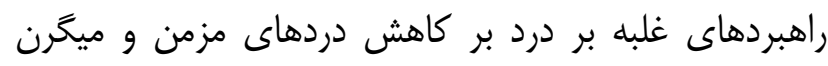

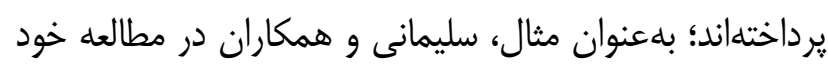

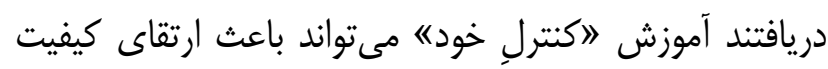

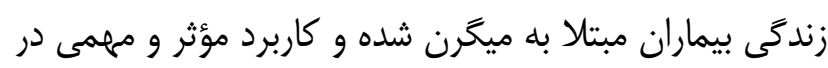

درمان بيماران مبتلا به ميخرن دارد (ألا().

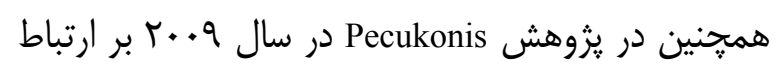

مقدمه

ميخرن، بلهنوان حملات مكرر سردرد و بلطور معمول

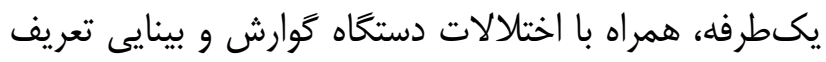
شده است (1). ميخرن به دو دسته كلى تقسيم شده است:

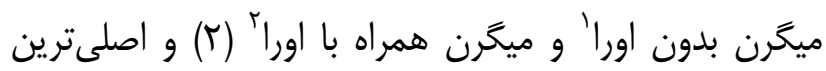

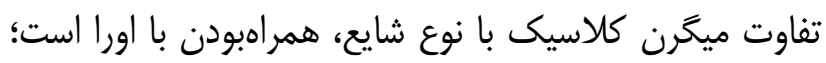

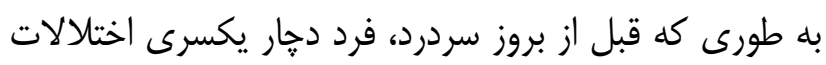

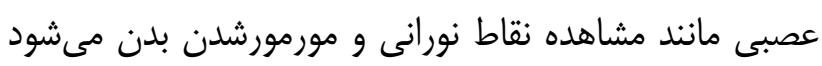

ميكَرن، شايعترين نوع سردرد با شيوع V تا Iا لا درصدى

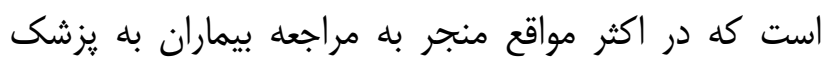

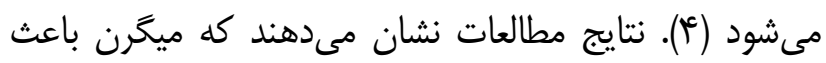

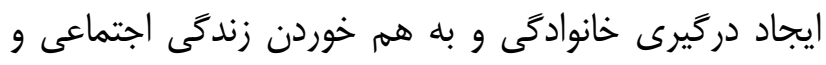

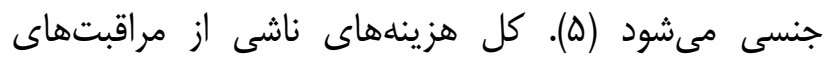

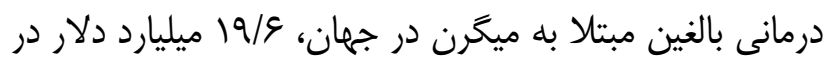

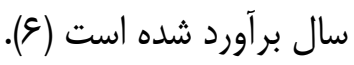
هنوز هيج روش درمانى ثابت و تأييدشدهاى براى درمان

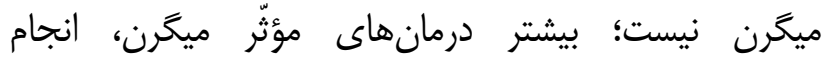

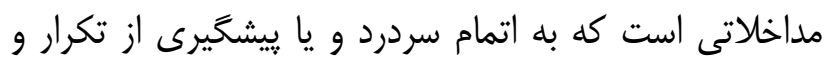

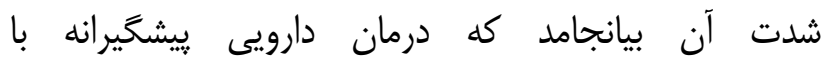
آَونيستهاى گيرنده سروتونين، بتابلوكرها و بلوكرهاى كان بانال كلسيه، درمان دارويى با هدف تسكين حملات درد و درمان

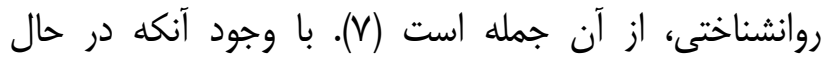

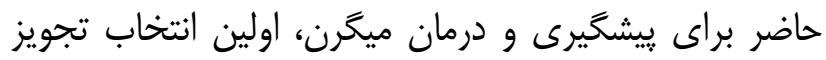

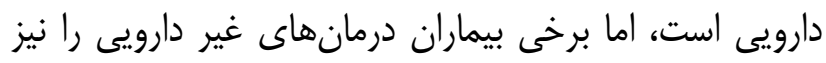

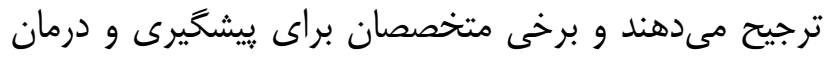
ميخرن اين درمانها را توصيه كردهاند (^). ييشرفتهاى نظرى و رشد فزاينده تحقيقات، مبانى لازم

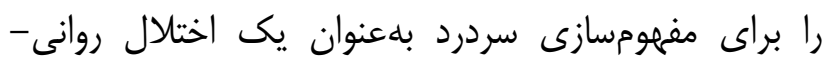

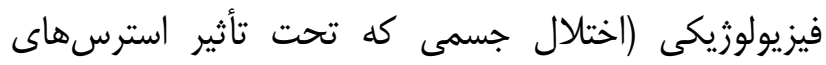

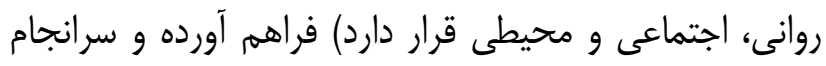


بنابراين، با توجه به شيوع بالاى انواع سردردها بهويزه

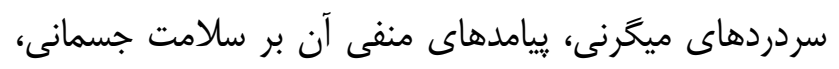

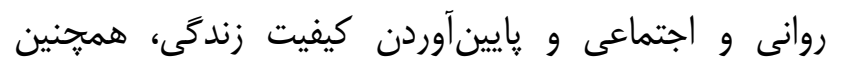
حمايت مطالعات از نقش تكميلى و سينرزيستى راهبردهائ باينى

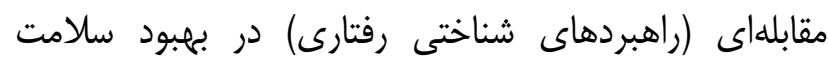

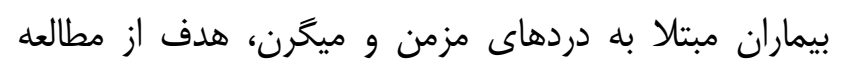

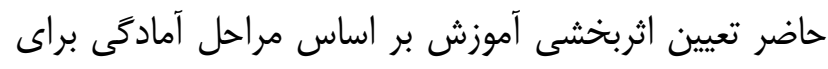

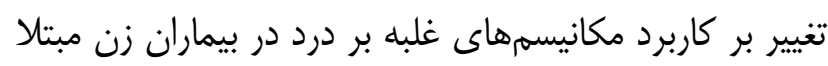

به ميكرن بود.

\section{روش تحقيق}

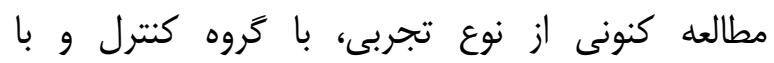

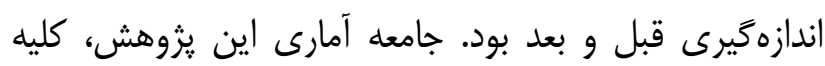

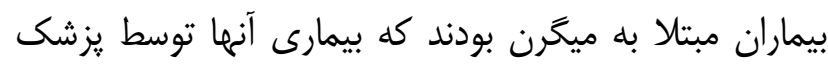

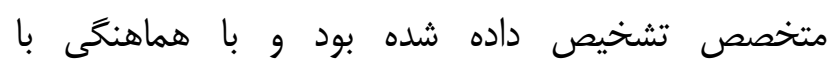

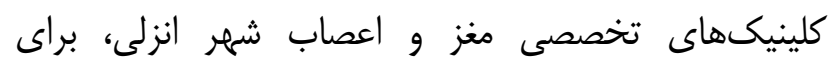

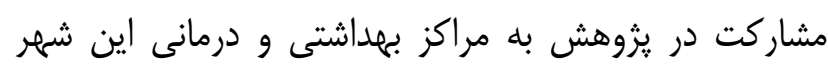

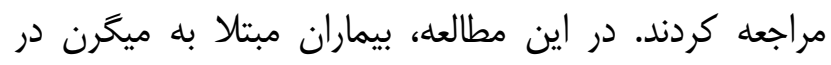

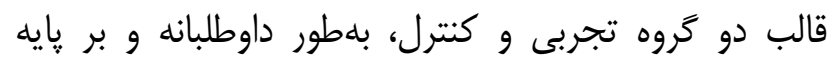

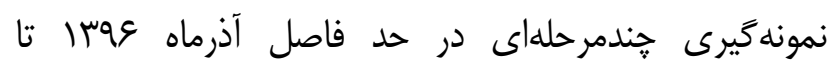

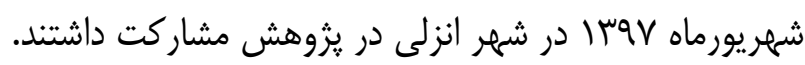

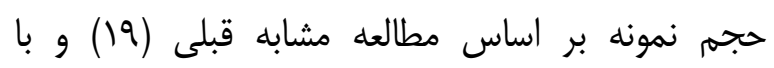

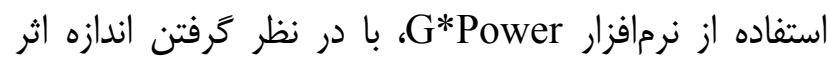

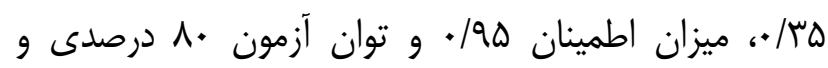

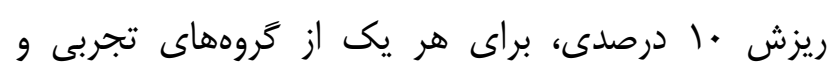

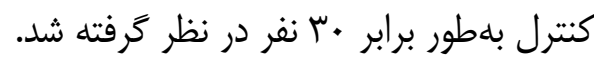

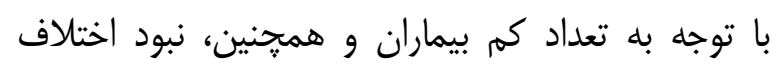

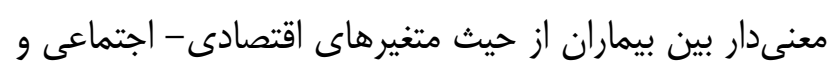

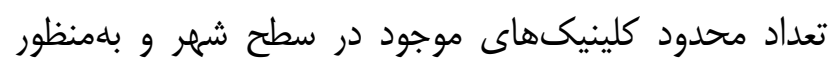
ييشگَيرى از برهميوشانى احتمالى بين نمونهها، ابتدا بلهصورت

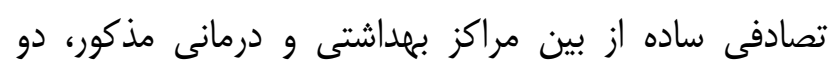

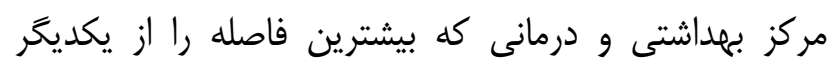

بين خودكارآمدى' و ساز كارى فرد با درد مزمن تأكيد كردهاند

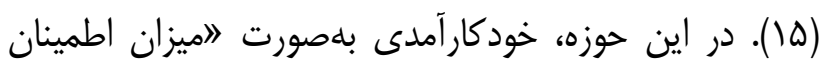

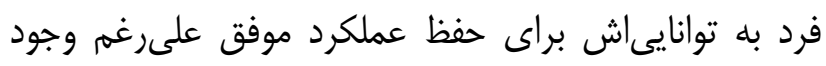
درده تعريف مىشود (•(1). مطالعات در خصوص تغيير رفتار به اين نتيجه رسيدهاند

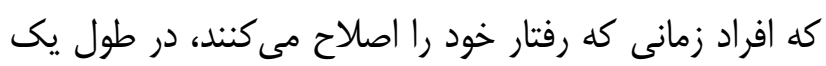

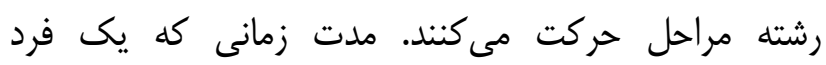

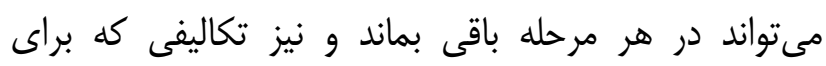

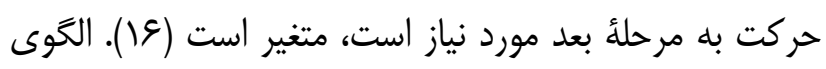

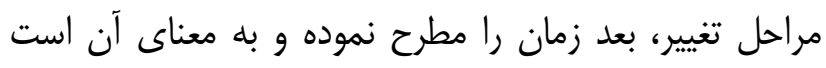

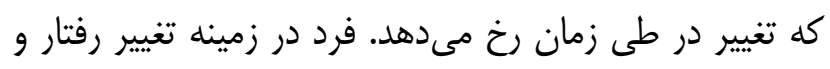

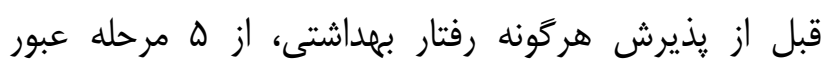

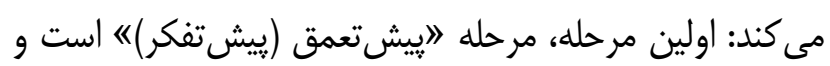

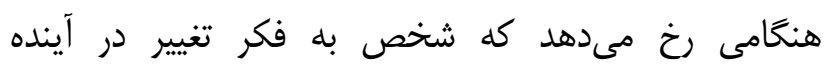

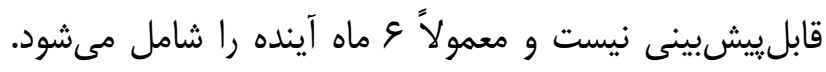

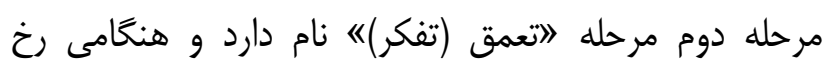

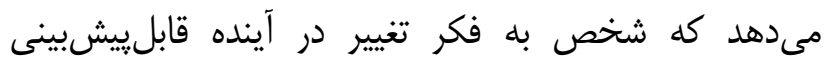

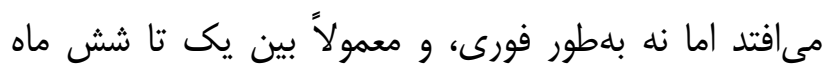

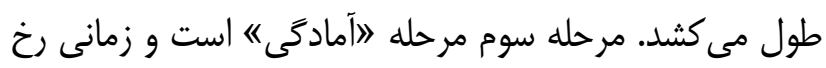

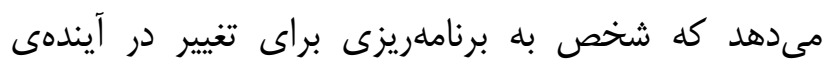

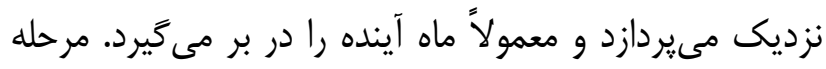

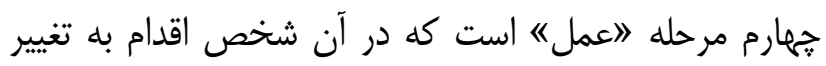

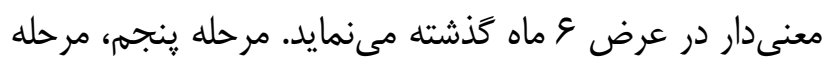

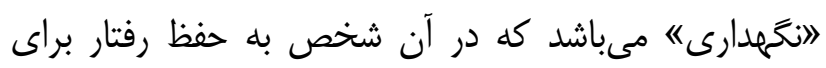
دورهاى از زمان مىيردازد و معمولاً مى گردد (IV). مدل مراحل تغيير را بلهعنوان الخوى كلى تلى تغيير

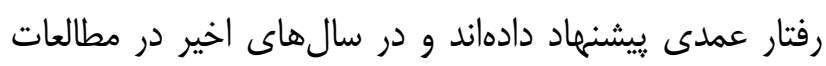

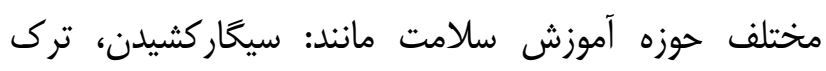

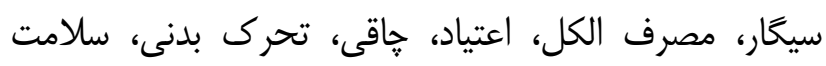

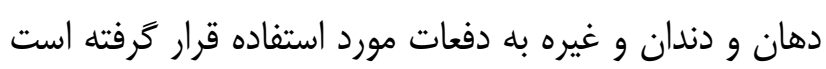

\section{${ }^{1}$ Self efficacy}

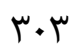


مهمرترين مشكل ناتوان كننده بيمارى، ابتلا به ساير بيمارىها،

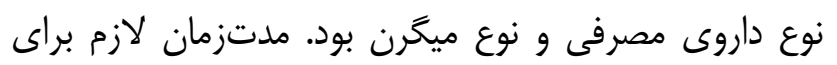

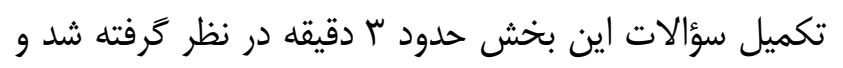

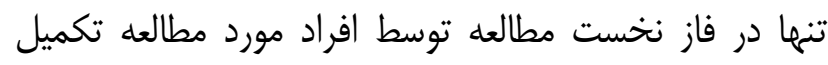
كرديد.

\section{يرسشنامه راهبردهاى مقابلهاى (Mouse و (Billings،}

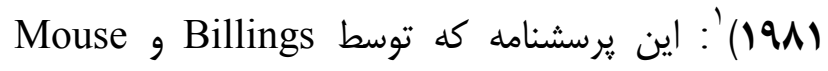
تهييه شده، داراى 19 سؤال در سه حيطه مقابلهشناختى

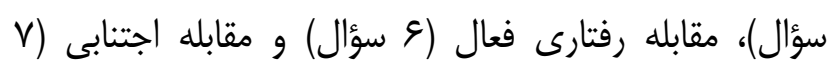

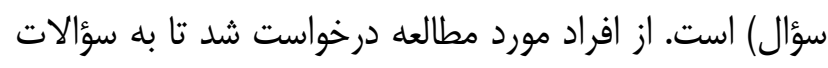

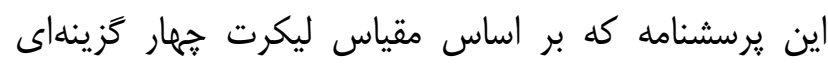

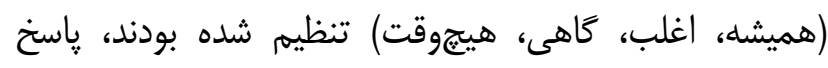

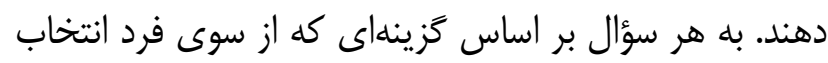

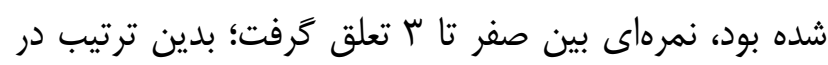

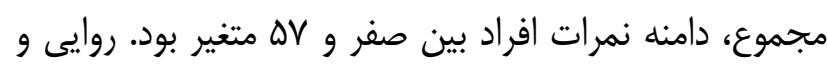

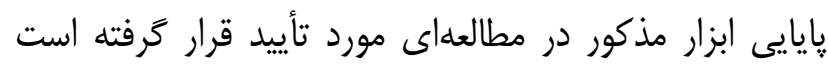

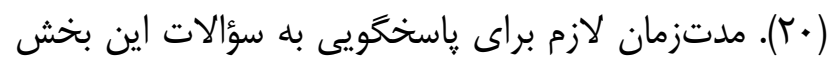

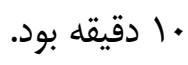

\section{يرسشنامه خودكارآمدى مربوط به درد (PSEQ)': اين}

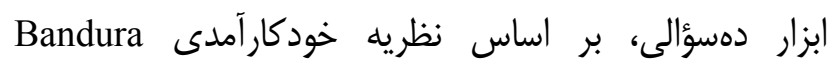

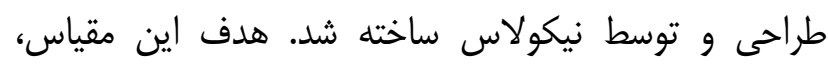

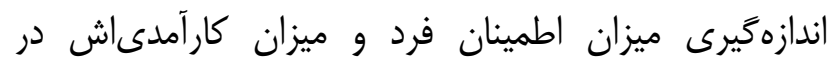

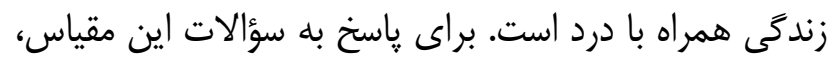

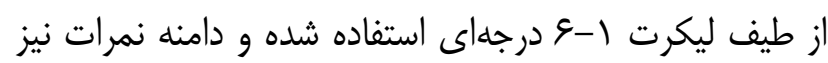

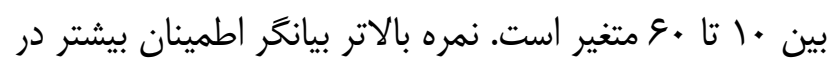

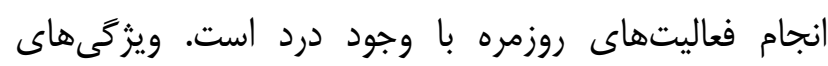

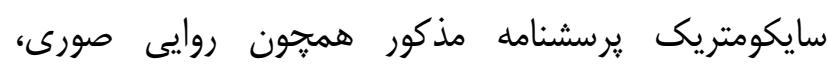

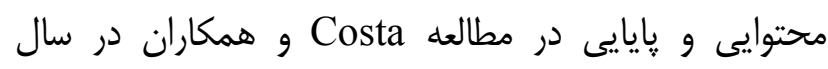

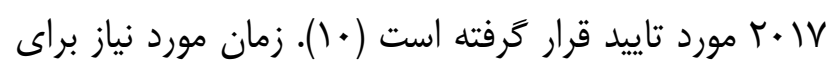
ياسخكُويى به سؤالات اين بخش تقريباً ه دقيقه بود.

\footnotetext{
${ }^{1}$ Billings and Mouse Coping Strategies Scale

${ }^{2}$ Pain Self Efficacy Questionnaire
}

داشتند، انتخاب شدند و يك مركز به گروه تجربى و مركز ديخر به گروه كنترل تخصيص داده شد. بعد از ثبتنام بيماران

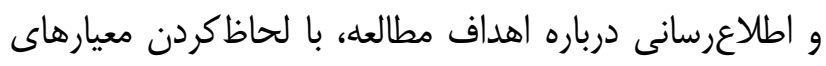
ورود و خروج و بر اساس جدول اعداد تصادفى، از بين افراد مذكور نمونه مَيرى انجام شد.

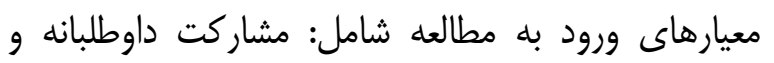

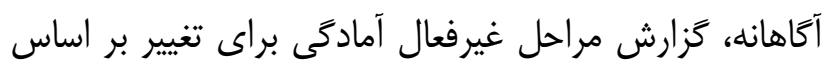

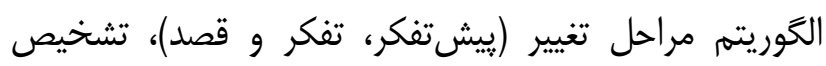

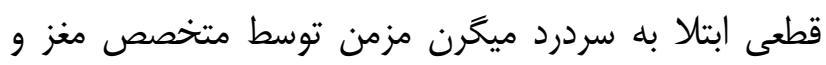

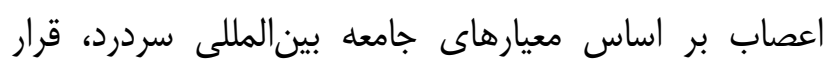

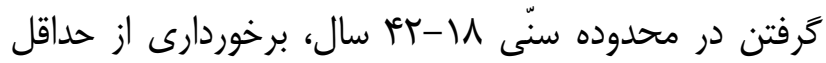

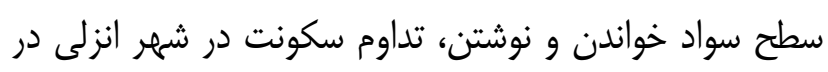

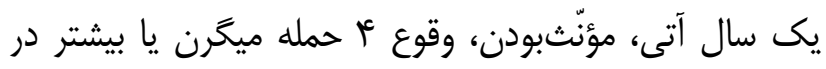

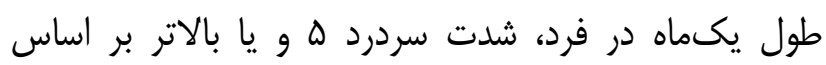
مقياس عددى سنجش درد، نداشتن شيفتهاى كارى در درد

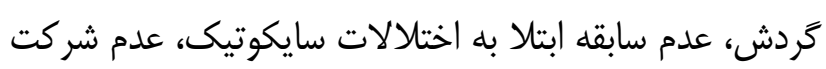

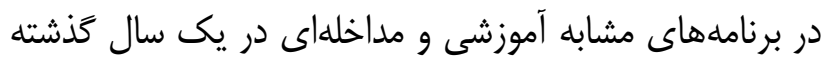

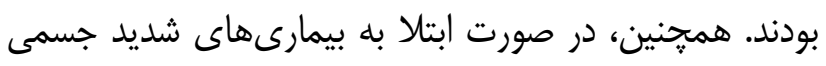

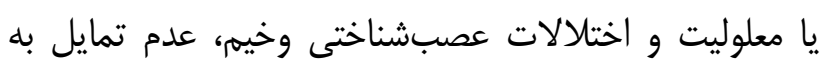
ادامه روند عادى درمان، بروز افكار خودكشى و يا احتمال

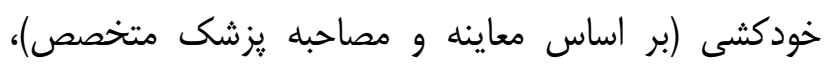

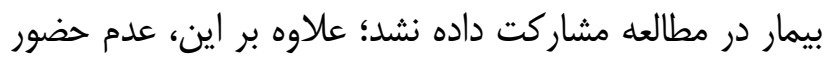

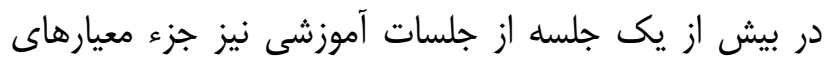
خروج در نظر كرفته شد.

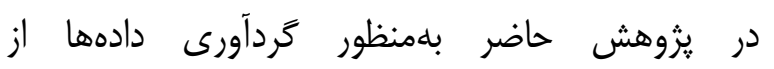
مقياسهاى مورد اطمينان و معتبر به شرح زير استفاده شد: يرسشنامه اطلاعات دموكر افيك و فردى: اين يرسشنامه

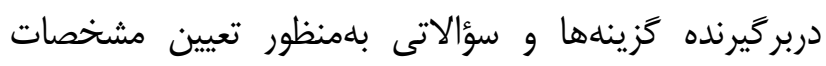

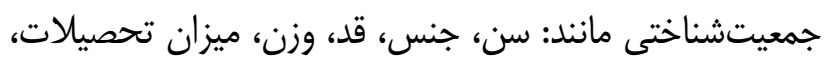

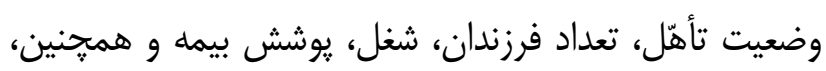

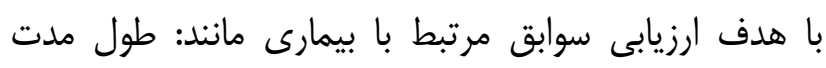

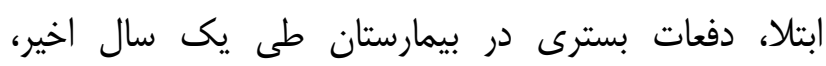


خبركان متشكل از كارشناس روانشناسى عمومى، روانشناس

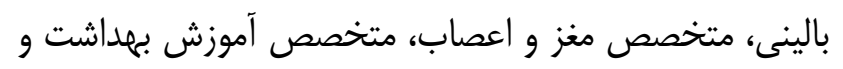

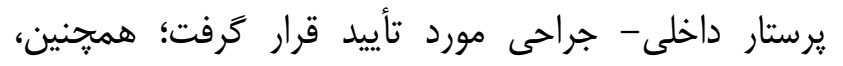

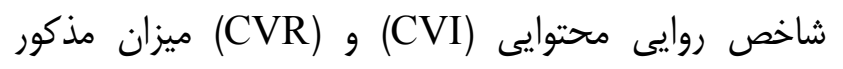

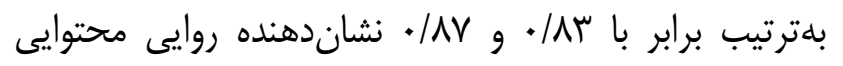

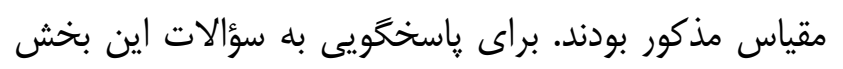
تقريبا V دقيقه زمان نياز بود.

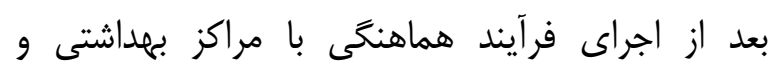
درمانى، كسب رضايتنامه كتبى و آكَاهىرسانى به به بيماران بهان

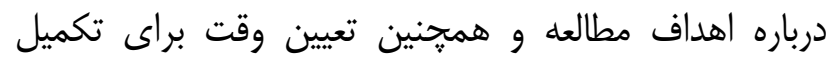

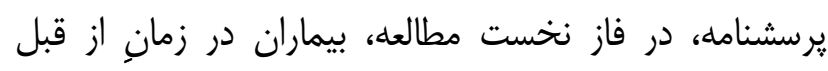

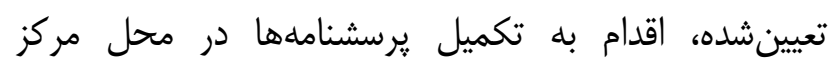

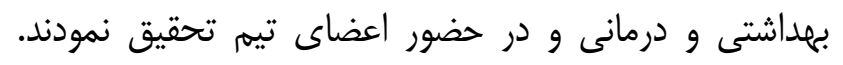

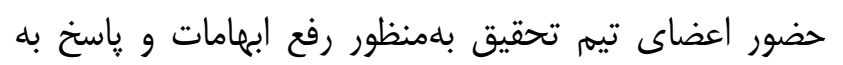

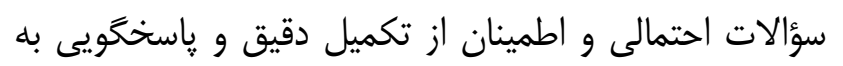
تمام سؤالات بود.

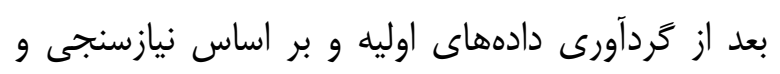

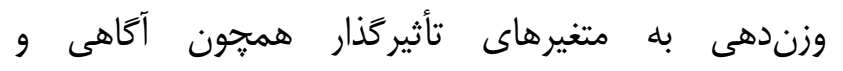

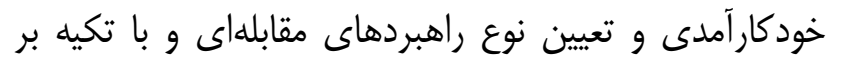

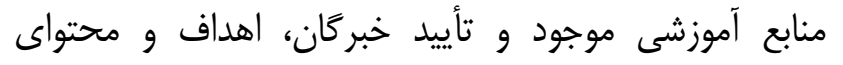

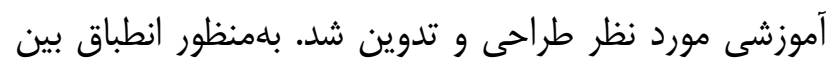

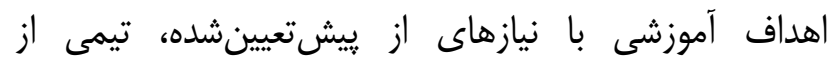

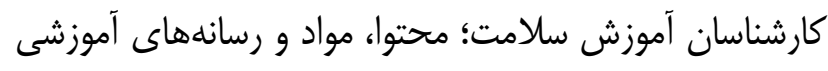

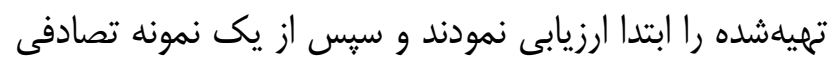

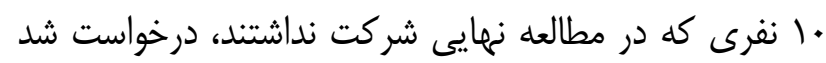

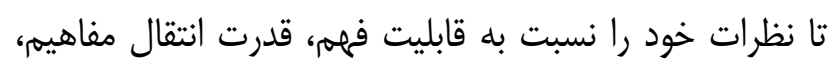

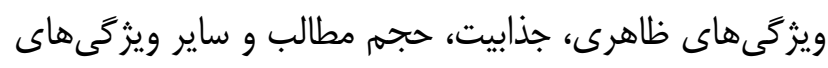

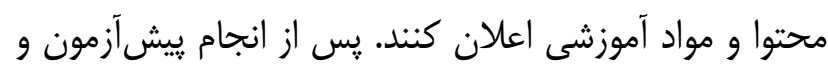

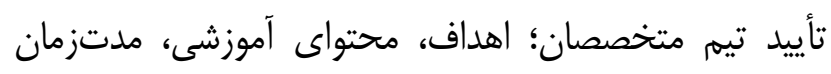

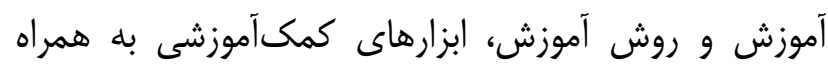

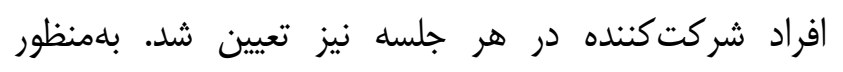
جلوكيرى از يكنواختبودن كلاس آموزشى و تسهيل فر فرآيند
الكوريتم مراحل تغيير درد': هدف مقياس مذكور،

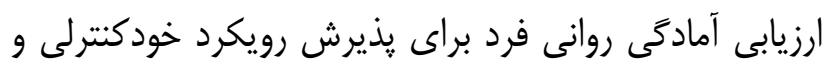

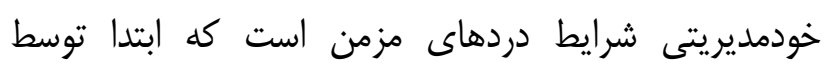

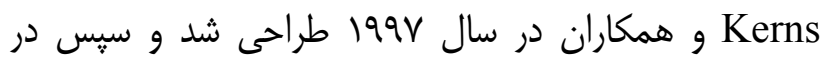

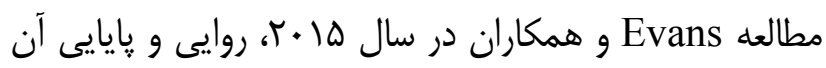

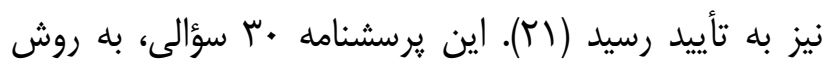

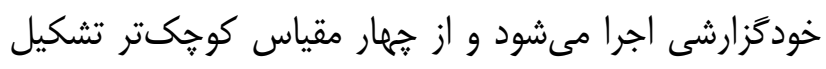

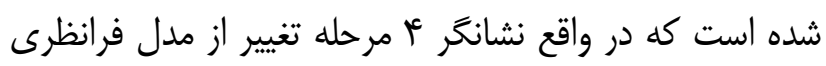

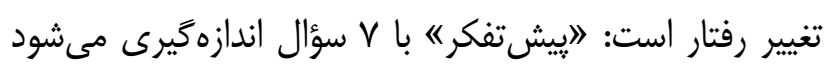

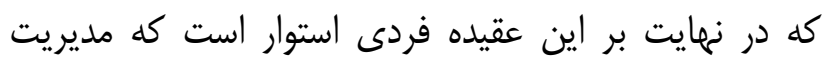

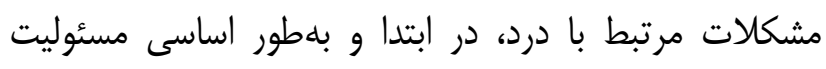

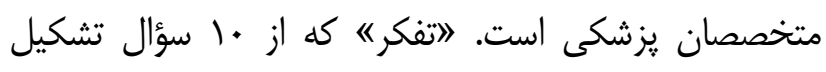

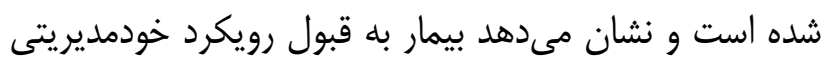

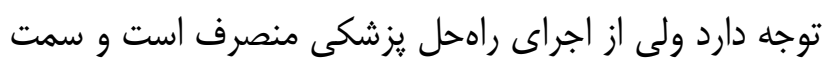

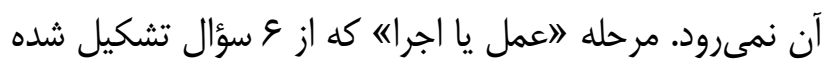

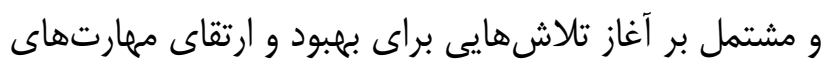

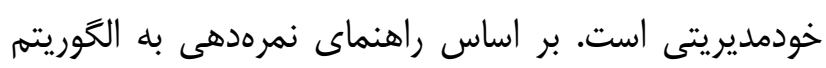

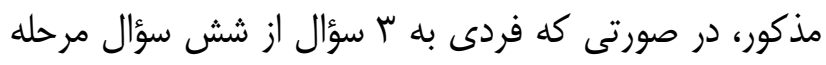

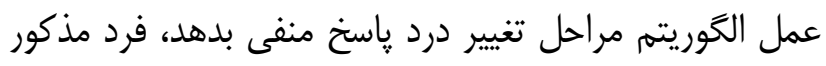

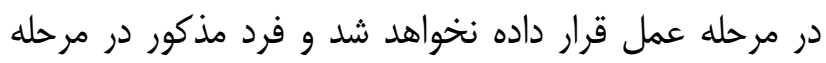

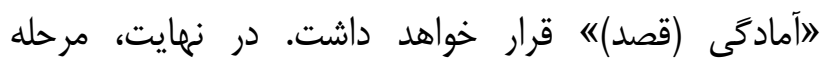

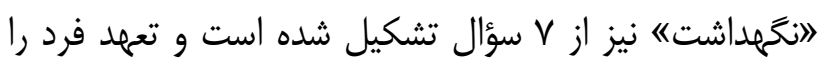

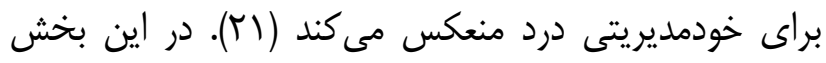

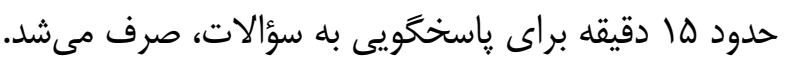
مقياس آَاهى: بر اساس مطالعه منابع و مقالات علمى

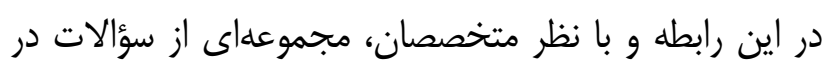

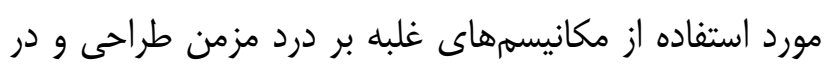

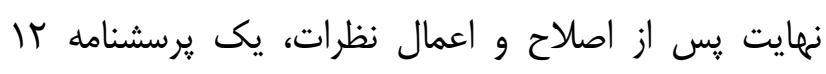

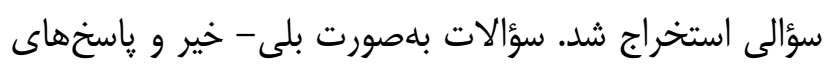

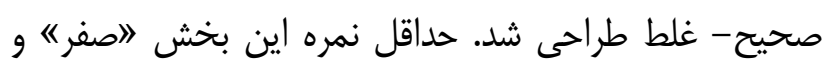
حداكثر "أبا" بود. روايى صورى يرسشنامه مذكور، توسط تيم 
عملى، تركيبى از روشهاى آموزشى مانند: سخنرانى، بحث

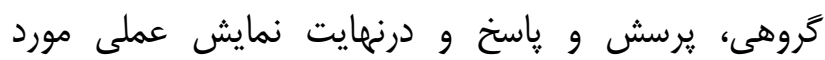

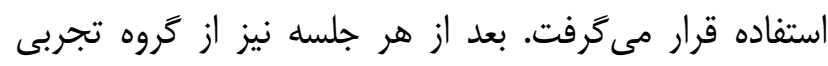

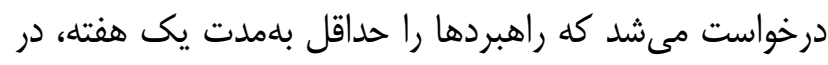

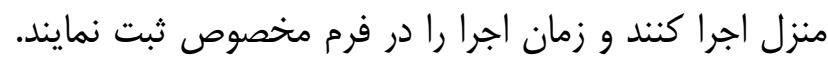

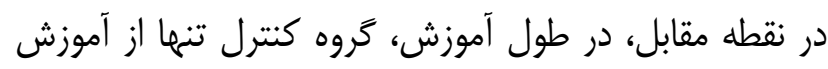

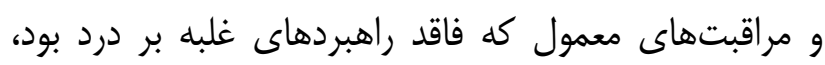
بهر ممند شدند.

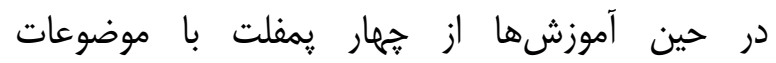
״ميكرن"، اطب فشارى"، "آياهان دارويى مؤثر بر درمان

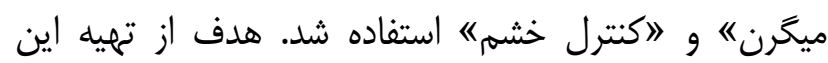

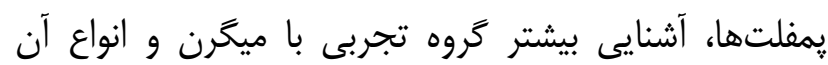

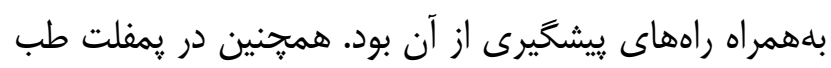

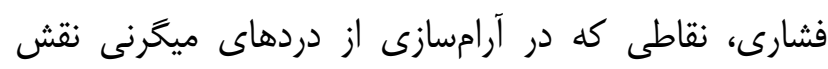

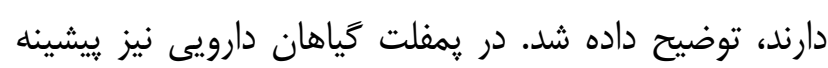

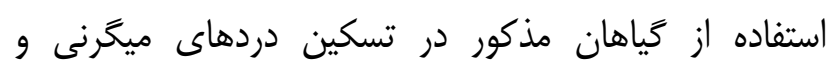

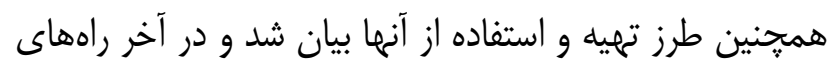

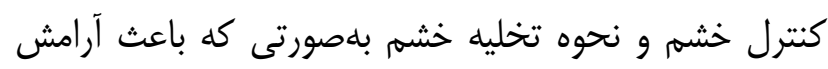
كردد، ارائه خرديد. در انتها پِ از تكميل يرسشنامهها، دادههاى جمع آورى

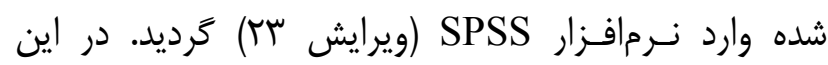

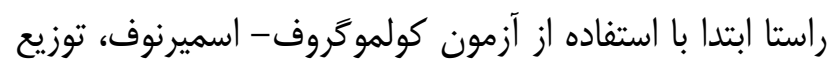

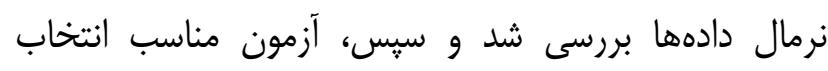

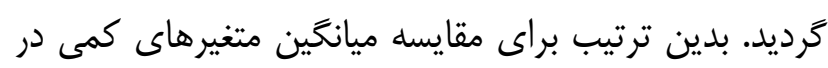

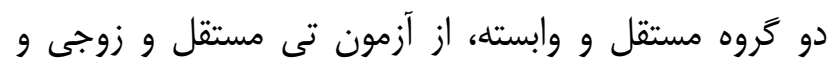
براى بررسى روابط متغيرهاى كيفى از آزمون كاى اسكوئر

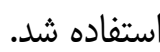

بلهنظور رعايت كرامت اخلاقى، محقـق يسس از ورود به

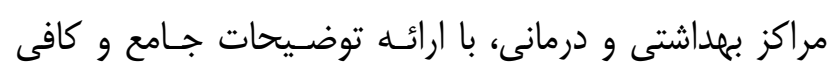

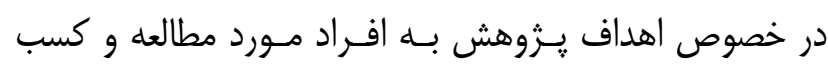

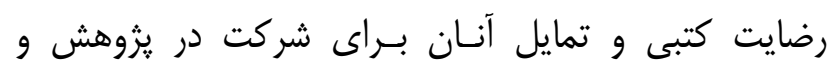

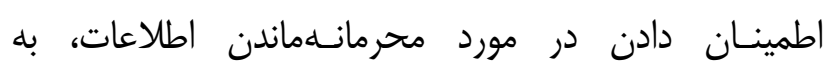

يادگيرى، از وسايل كمكآموزشى نظير يمفلت و يوستر و

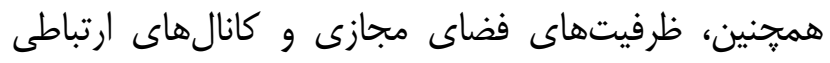
مانند سروش و WhatsApp استفاده شد و و با استفاده از

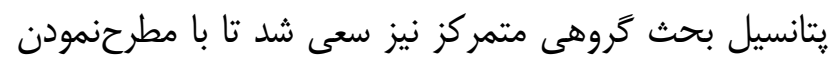

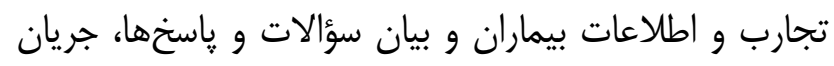

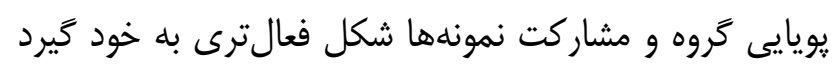

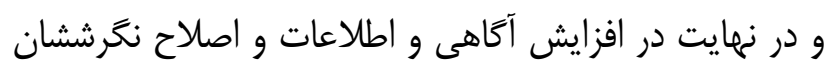
اثر خذار باشد.

در انتها، آموزش داده شده به كروه تجربى شامل ه جلسه

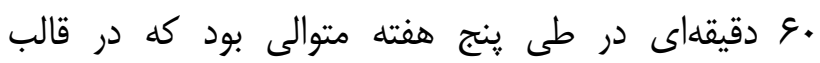

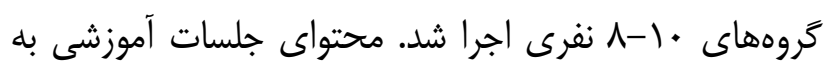
اين شرح بود: جلسه اول شامل: تعريف و مقايسه انواع سردردهاى حاد و مزمن، مكانيسمها و علل احتمالى، علائم و

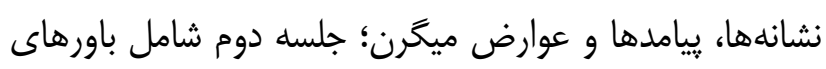

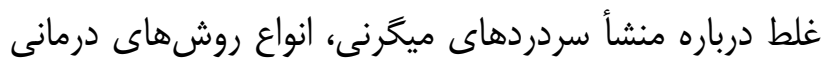

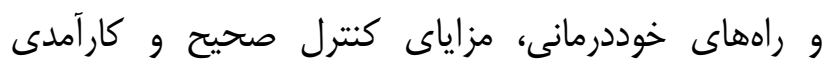
روشهاى غيردارويى مقابله با سردردهاى ميكَرنى؛ جلسه

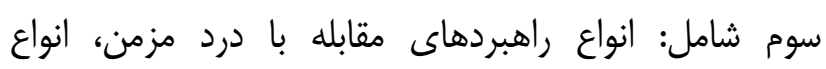

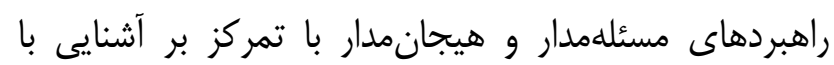
راهبردهاى حل مسئله، مديريت خشهم و اضطراب، آموزش مهان كنترل تكانه و هيجان و ساير راهبردها؛ جلسه جهمار مهارم شامل: نمايش عملى و اجراى راهبردهاى آموزش داده شده به همراه

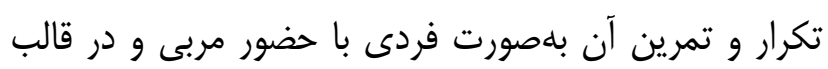
فعاليتهاى گروهى و در نهايت جلسه ينجم شامل: يادآورى و مرورى بر مباحث مطرحشده، ياسخ بله سؤالات، بازخورد كلامى و تشويق در راستاى تكرار و ماندًارى راهبردهاى ئد ياد كرفته شده بود. در طول تمام جلسات، نخست آموزش نظرى از سوى ملود

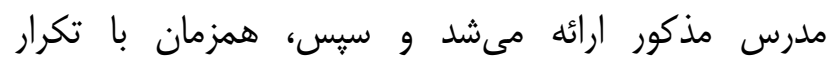

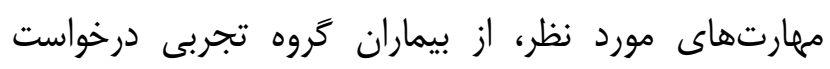

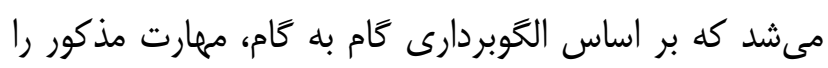

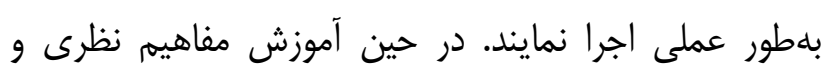


جمعآورى اطلاعات يرداخت. همجنين، يزوهش مذكور از نداد.

يافتههاى درجشده در جدول r نشان مىدهد بين دو

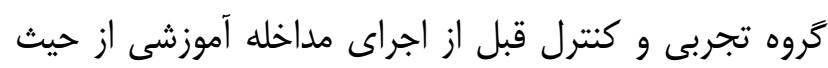

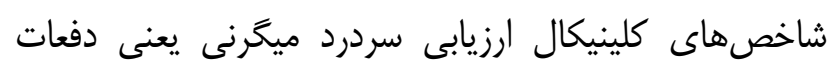

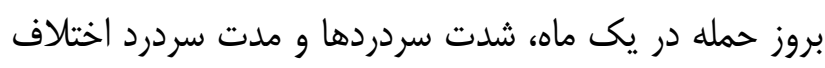

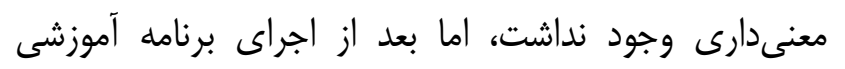

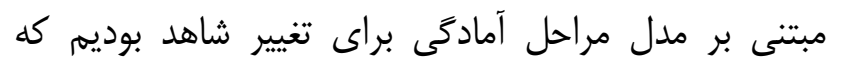

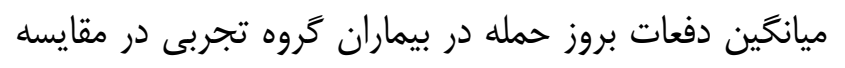

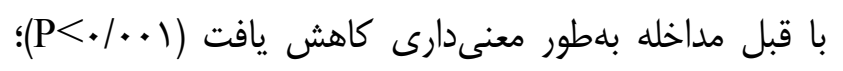

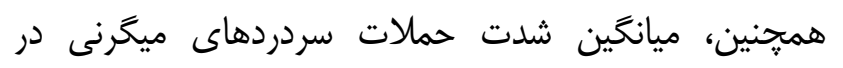

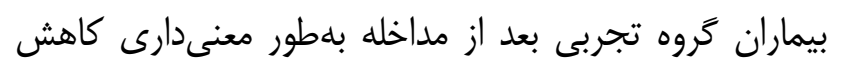

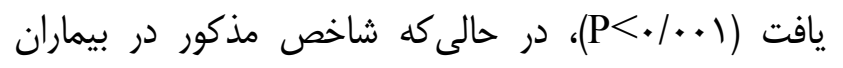

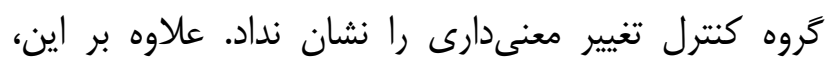

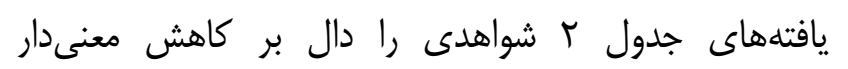

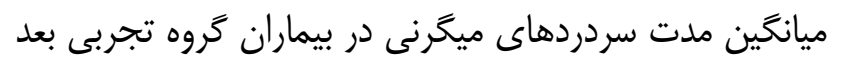

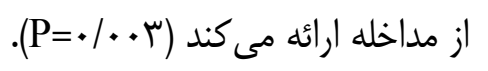

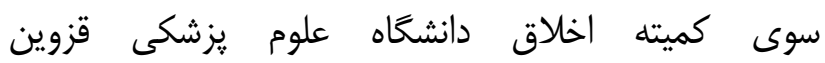
(IR.QUMS.REC.1396.353) مورد تأييد واقع شدم.

\section{يافته ها}

نتايج درجشه در جدول يك به مقايسه ويزگى دهاى

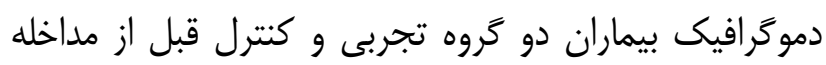

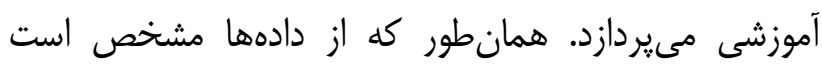

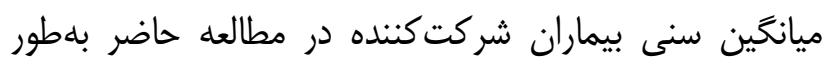

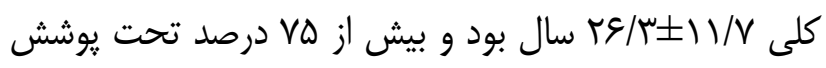

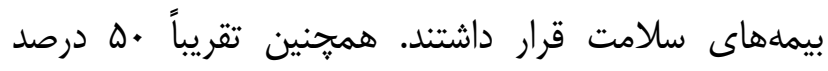

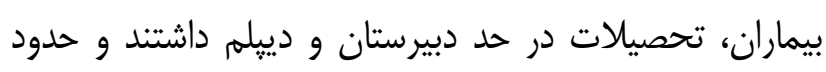
V.

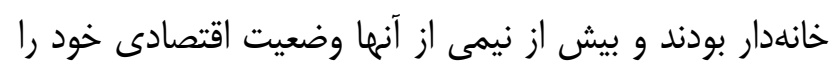

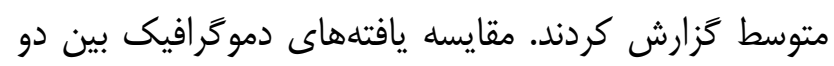

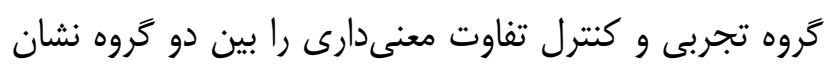

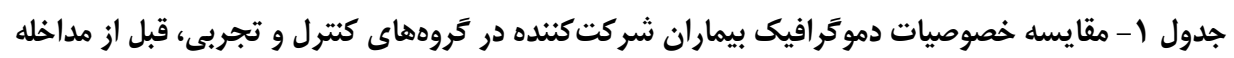

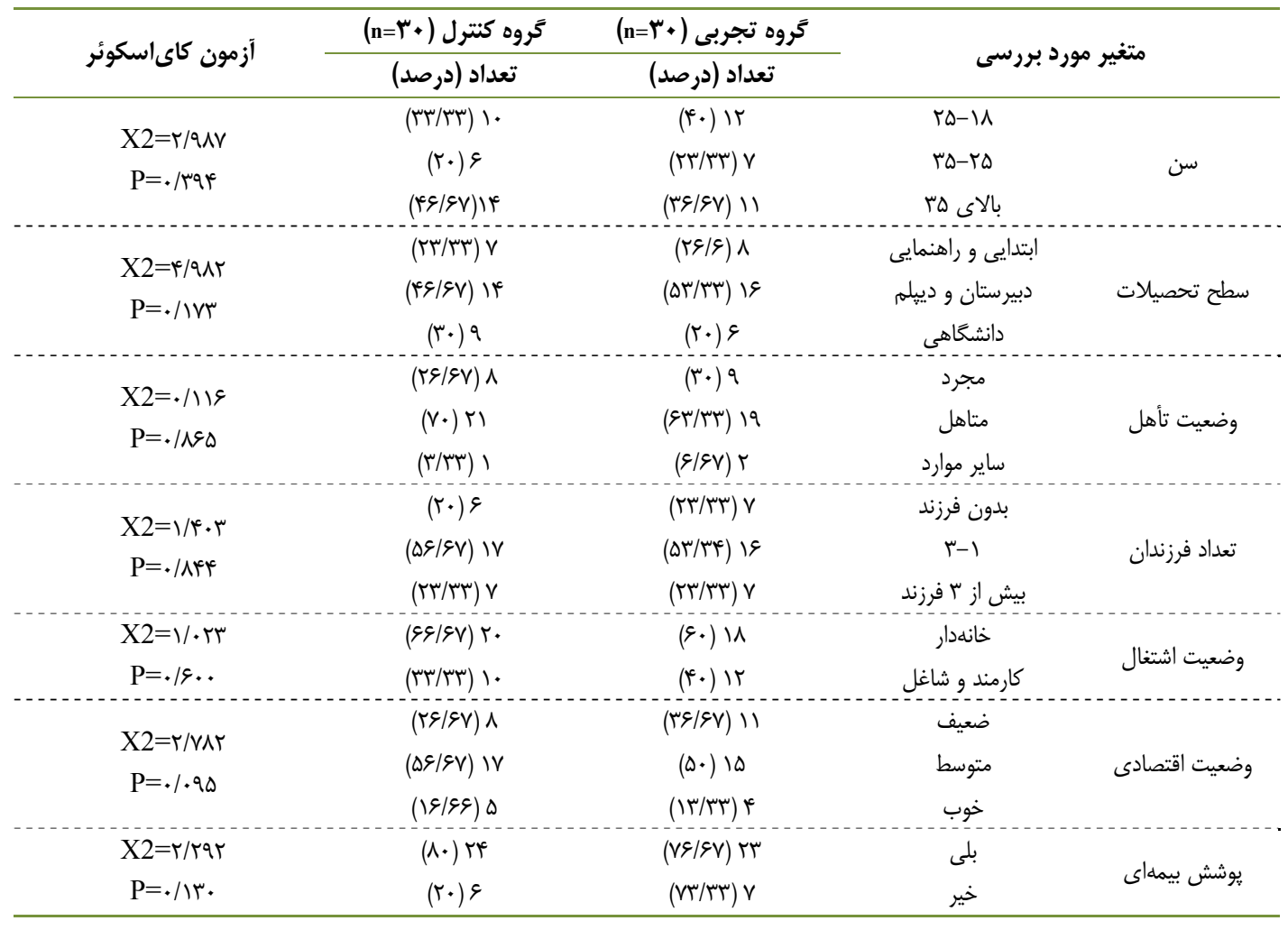


جدول r - شاخصهاى مربوط به سردردهاى ميكَرنى در بيماران تَروههاى كنترل و تجربى، قبل و بعد از مداخله آموزشى

\begin{tabular}{|c|c|c|c|c|}
\hline آزمون تىزوجى & بعد از مداخله & قبل از مداخله & \multicolumn{2}{|c|}{ شاخص مورد بررسى } \\
\hline $\mathrm{t}=-\mathrm{r} / \varepsilon \Delta \Phi, \mathrm{P}<\cdot / \cdots 1$ & $1 / q u \pm 1 / \cdot V$ & $p / r q \pm 1 / \kappa$ & كروه تجربى & \multirow{2}{*}{ دفعات حمله در طول يك ماه } \\
\hline $\mathrm{t}=-1 / / \uparrow \cdot{ }^{\mathrm{P}} \mathrm{P}=\cdot / \mathrm{q} \mathrm{D}$ & $\Gamma / १ \Delta \pm 1 / \& \Delta$ & $r / r \mid \pm I / r \Lambda$ & كروه كنترل & \\
\hline- & $\mathrm{t}=r / \Delta \& V, \mathrm{P}<\cdot / \ldots 1$ & $\mathrm{t}=1 / \mathrm{F}^{\mathrm{C}} \mathrm{r} \cdot \mathrm{a}=\cdot / / \Delta \Lambda$ & آزمون تىمستقل & \\
\hline $\mathrm{t}=\varepsilon / \wedge \Delta \wedge, \mathrm{P}<\bullet / \ldots)$ & $r / V T \pm I / A V$ & $\Lambda / \mu F \pm 1 / \Delta S$ & عروه تجربى & \multirow{3}{*}{ شدت سردرد } \\
\hline $\mathrm{t}=\cdot / q \cdot r, \mathrm{P}=\cdot / \mu \mathrm{r} \cdot$ & N/RMII/R & $1 / \varepsilon \cdot \pm 1 / \uparrow q$ & كروه كنترل & \\
\hline- & $\left.\mathrm{t}=-\mu / \Lambda \varepsilon \cdot{ }_{\mathrm{C}} \mathrm{P}<\cdot / \cdot \cdots\right)$ & $\mathrm{t}=\cdot / \mathrm{q} q 1 \mathrm{P}=\cdot / 9 q 1$ & آزمون تى مستقل & \\
\hline 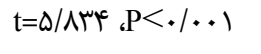 & $r /\|r \pm\| / . \varphi$ & $r / \Lambda \Delta \pm 1 / \mu^{c}$ & كروه تجربى & \multirow{3}{*}{ مدت سردرد } \\
\hline $\mathrm{t}=-\cdot\left|\boldsymbol{F}^{\mu} \cdot{ }^{\prime} \mathrm{P}=\cdot\right| \Delta{ }^{\mu} \mid$ & $\Gamma / \mu \wedge \pm 1 / V$ & $r / \Delta q \pm 1 / v$. & گروه كنترل & \\
\hline- & $\mathrm{t}=-\mathrm{r} / \mathcal{F} V(\mathrm{P}=\cdot / \ldots 1$ & 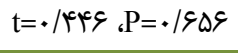 & آزمون تىمستقل & \\
\hline
\end{tabular}

جدول بـ- مقايسه ميانكين راهبردهاى مقابله اي در بيمار ان تروه هاى تجربى و كنترل قبل و بعد از مداخله

\begin{tabular}{|c|c|c|c|c|}
\hline آزمون تىزوجى & بعد از مداخله & قبل از مداخله & ترووه & راهبرد مورد استفاده \\
\hline $\mathrm{t}=-\Delta / \mathrm{V} \wedge \mathrm{V}, \mathrm{P}<\cdot / \cdots)$ & $\mid \varepsilon / / r \pm \Psi / V \Delta$ & $r / r q \pm r / M$ & تجربى & \multirow{3}{*}{ راهبرد مقابله مواجهه } \\
\hline $\mathrm{t}=-\cdot / \mathrm{T} \Delta \mathrm{Q}$ ، $\mathrm{P}=\cdot / \mathrm{VT})$ & $\mid r / \Delta H \pm \Psi / I V$ & $\mid r / r \cdot \pm r / q r$ & كنترل & \\
\hline- & $\mathrm{t}=\Delta / \mathrm{q}_{\mathrm{q}}{ }_{\mathrm{g}} \mathrm{P}<\cdot / \cdots 1$ & 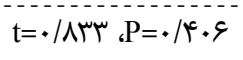 & آَّآمون تى مستقا & \\
\hline $\mathrm{t}=-\mathrm{V} / \mathrm{N} / 1 \mathrm{~d}<</ \cdots 1$ & $\mid K / G \cdot \pm T / K F$ & $\mid Q / \mu F \pm Y / A V$ & تجربى & \multirow{3}{*}{ راهبرد فاصله گيرى } \\
\hline $\mathrm{t}=-\cdot / \mathrm{rv} \cdot{ }_{\mathrm{C}} \mathrm{P}=\cdot / \mathrm{V} / \mathrm{m}$ & $\mid \phi / \mu \wedge \pm \mu / 1$ & $\mid Q / V \& \pm \mu / \cdot \mathcal{F}$ & كنترل & \\
\hline- & $\left.\mathrm{t}=\mathrm{V} / \mathrm{TAV}{ }_{\mathrm{C}} \mathrm{P}<\bullet / \cdots\right)$ & 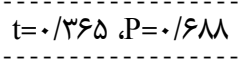 & آَّمون تى مستقا & \\
\hline 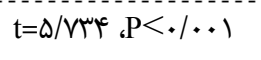 & $19 / 8 \mid \pm r / \Lambda \Delta$ & l $/ T \Delta \pm \mu / V \mu$ & تجربى & \multirow{3}{*}{ خود كنترلى } \\
\hline $\mathrm{t}=-\cdot\left|q \mu \cdot{ }_{\mathrm{C}} \mathrm{P}=\cdot\right| \Delta{ }^{\mathrm{W}}$ & $\mid V / \cdot \wedge \pm \Psi / F F^{C}$ & $\mid \varepsilon / q \uparrow \pm r / \wedge \varepsilon$ & كنترل & \\
\hline- & $\mathrm{t}=\mathrm{r} / \mathrm{F} \mathrm{N}, \mathrm{P}<\cdot / \cdots)$ & $\mathrm{t}=. / 4 \uparrow 9, \mathrm{P}=. / 9 \Delta \Delta$ & آَّمون تىمستقا & \\
\hline $\mathrm{t}=\mathrm{N} / \Delta$ \& ${ }^{\prime} \mathrm{P}<\cdot / \cdots 1$ & $|V / T \cdot \pm r / /|^{c}$ & $19 / 1 r \pm r / 9 V$ & تجربى & \multirow{3}{*}{ جستجوى حمايت } \\
\hline $\mathrm{t}=-\cdot / T \Delta\left|{ }_{\mathrm{C}} \mathrm{P}=\cdot\right| \Delta T_{1}$ & $\mid q / V D \pm r / \cdot q$ & 1 $1 / R T \pm r / \Lambda \Delta$ & ـ ـ ـ & \\
\hline- & $\mathrm{t}=\mathrm{N} / \Delta Y \Lambda, \mathrm{P}<\cdots / \cdots)$ & $\mathrm{t}=\cdot / q \cdot \mathrm{r}_{\mathrm{C}} \mathrm{P}=\cdot / / 49$ & آَّمون تىمستقا & \\
\hline $\mathrm{t}=-\mathrm{r} / \Lambda \mathrm{N} \mid \mathrm{I}(\mathrm{P}<\cdot / \cdot+1$ & $1 \mathrm{~T} / \Delta \mathrm{V} \pm \mathrm{r} / \mathrm{/q}$ & $1 / / \sigma \Delta \pm r / \mathcal{L} \varepsilon$ & تجربى & \multirow{3}{*}{ يذيرش مسئوليت } \\
\hline $\mathrm{t}=-1 / \Lambda \mathrm{r} \cdot \mathrm{d} \mathrm{P}=\cdot / \mathrm{T} \Delta \Lambda$ & $11 / r س \Psi \pi / I V$ & $11 / T V \pm r / \cdot 1$ & كنترل & \\
\hline- & $\mathrm{t}=r / \Delta \& V, \mathrm{P}<+/ \cdots)$ & $\mathrm{t}=1 / / \mathrm{T} \cdot{ }^{\prime} \mathrm{P}=\cdot / / \Delta \Lambda$ & آَزمون تى مستقا & \\
\hline $\mathrm{t}=-r^{\mathrm{c}} / \mathrm{Vq} \cdot \mathrm{a}<<\cdot / \cdot 1$ & g & $10 / 4 \cdot \pm r / 94$ & تجربى & \multirow{3}{*}{ فرار-اجتناب } \\
\hline $\mathrm{t}=-\cdot / 9 \cdot 1 ، \mathrm{P}=\cdot /$ r $9 q$ & $\mid Q / \wedge r \pm r / \cdots$ & $\mid Q / \wedge \mu \pm r / 1 \varphi$ & كنترل & \\
\hline- & $\mathrm{t}=\Delta / \cdot \mathrm{V}^{\mathrm{N}}{ }_{\mathrm{r}} \mathrm{P}<\cdot / \cdot \cdots 1$ & $\mathrm{t}=1 / / \mathrm{M}{ }_{\mathrm{C}} \mathrm{P}=\cdot / \mathrm{r} \cdot \mathrm{r}$ & آَّمون تى مستقا & \\
\hline $\mathrm{t}=-\mathrm{H} / \mathrm{L \Lambda} ، \mathrm{P}<\cdot / \cdots)$ & $\mid V / r \Delta \pm r / r$ & $\mid \omega / \mu r \pm \Gamma / 1 q$ & تجربى & \multirow{3}{*}{ لـ مسئله برنامهريزىشده } \\
\hline $\mathrm{t}=-\cdot / \varepsilon \cdot \Delta, \mathrm{P}=\cdot / \Delta \mathrm{F}^{\mathrm{V}} \mathrm{V}$ & $1 Q / Q Y \pm r / A r$ & $\mid \phi / q \Psi \pm \Psi / \Delta \xi$ & كنترل & \\
\hline $\begin{array}{l}- \\
-\end{array}$ & • & .109 & آَّمون تى مستقا & \\
\hline $\mathrm{t}=-\cdot / \mathrm{Tr} \mathrm{\omega}_{\mathrm{C}} \mathrm{P}=\cdot / \mathrm{V} / 9$ & $r \cdot / \mu Y \pm T / \Delta q$ & 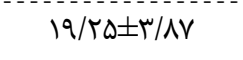 & تجربى & \multirow{3}{*}{ ارزيابى مجدد مثبت } \\
\hline $\mathrm{t}=-\cdot / 9) \vee \mathrm{P}=\cdot / \Delta \mathrm{M} \Lambda$ & 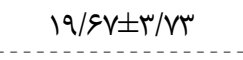 & $r \cdot / \cdot \cdot \pm r / \mu$ & كنترل & \\
\hline- & $\mathrm{t}=\cdot / \mathrm{q} \cdot \mathrm{r}, \mathrm{P}=\cdot / \mathrm{rV}$ & $\mathrm{t}=\cdot / \mathrm{HV}{ } \mathrm{P}=\cdot / \mathrm{V} / T$ & آَّزمون تىمستقا & \\
\hline
\end{tabular}


دادهها مىتوان نتيجه كرفت كه بالاترين نمره براى مراحل

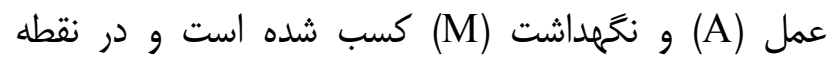

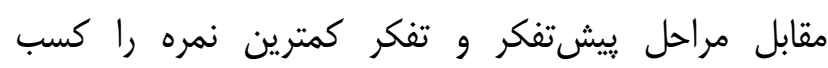

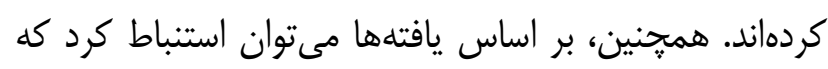

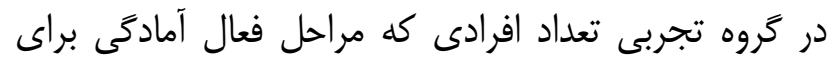

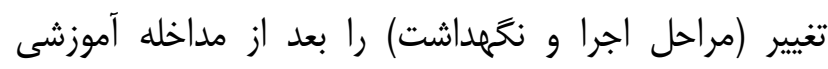
كزارش كردند، بلهور معنىدارى در مقايسه با قبل از مداخله

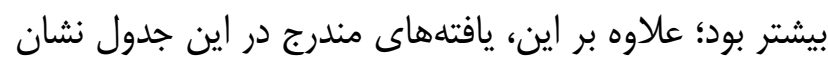

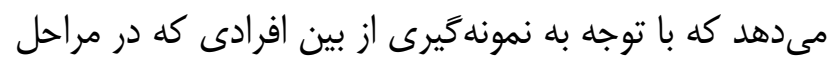
غير فعال قرار داشتند (ييشتفكر، تفكر و و آمادكى)، هيج نيج بيمارى كه هنغام مطالعه از راهبردهاى مقابلهاى با سردرد

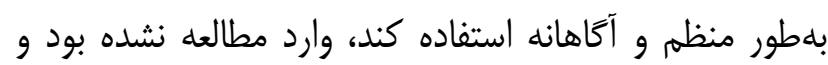

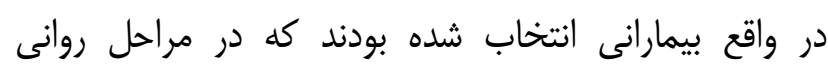

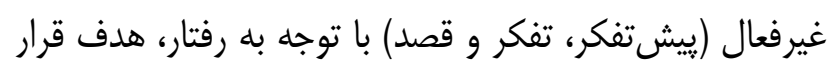
داشتند. همجنين بررسى سطحى توزيع افراد بر اساس سازه

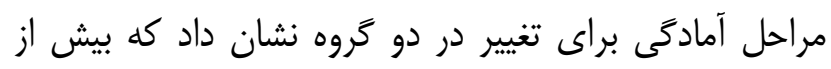

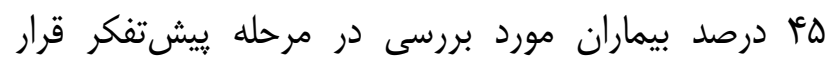

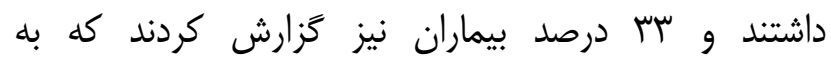

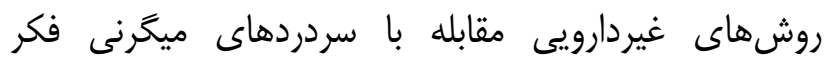

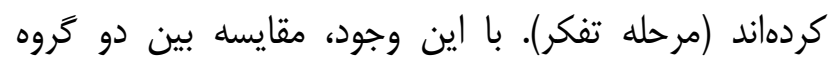

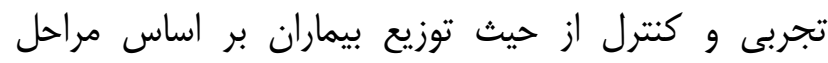

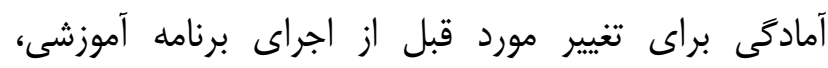

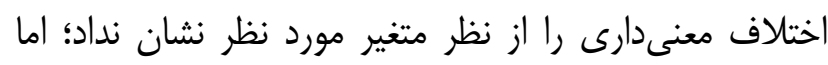

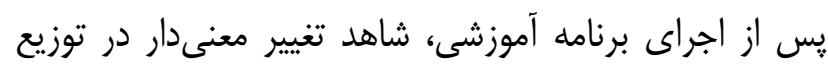

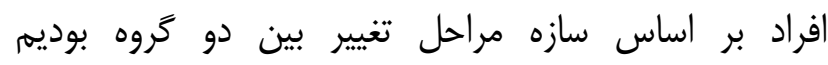

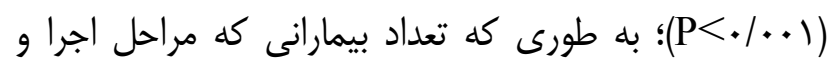

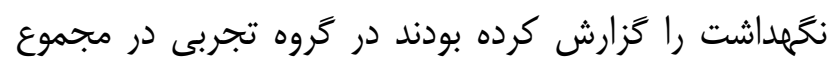

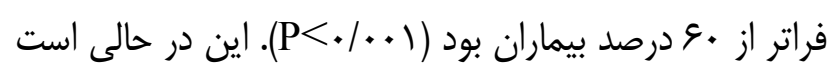

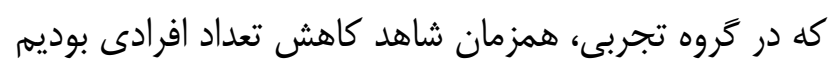

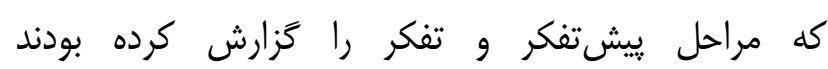
$(\mathrm{P}<\cdot / \cdots)$
نتايج مندرج در جدول ، منعكس كننده مقايسه ميانخين دفعات كاربرد انواع راهبردهاى مقابلهاى بين بيماران مبتلا بـ به منيه

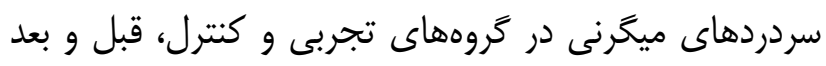

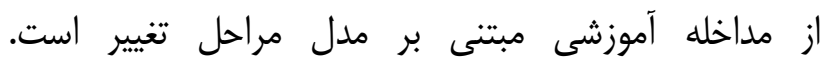
همانطور كه از دادهها استنتاج مى

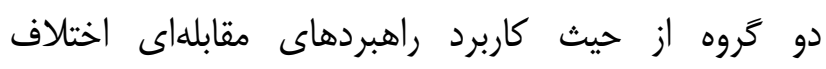

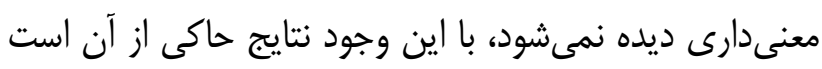

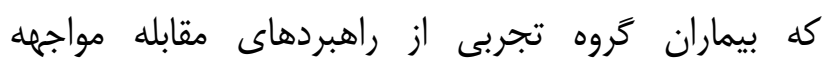

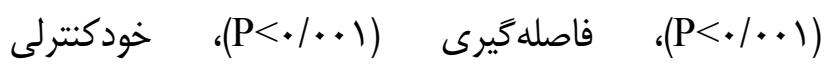

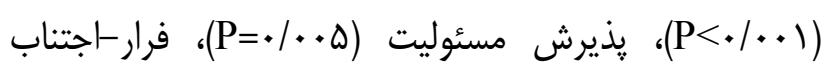

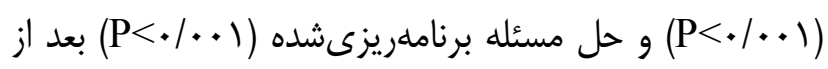
مداخله مبتنى بر مراحل تغيير بلهور معنىدارى بيشتر استفاده

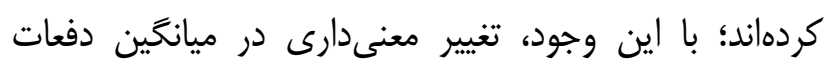

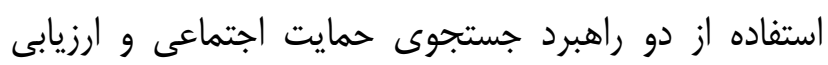

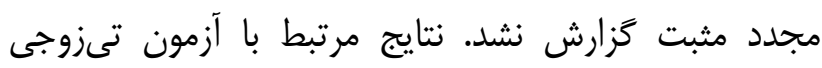

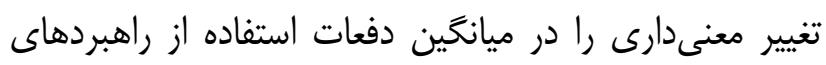

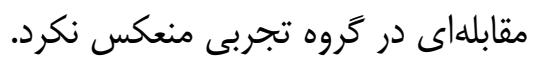

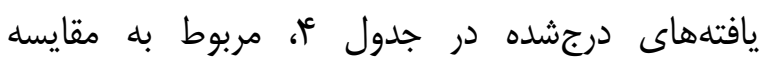

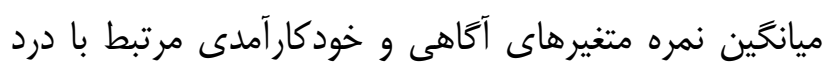

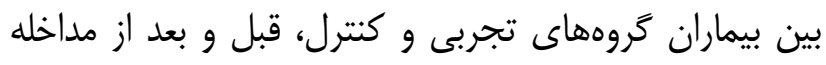
آموزشى است. مقايسه ميانخين دو متغير مذكور بين بيماران

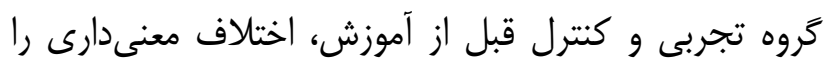

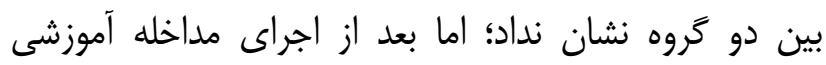

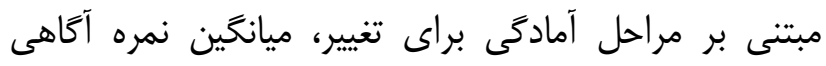

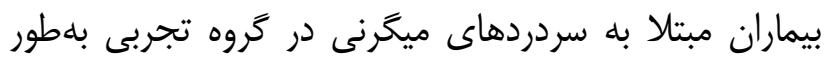

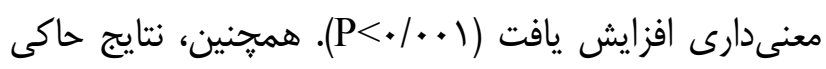

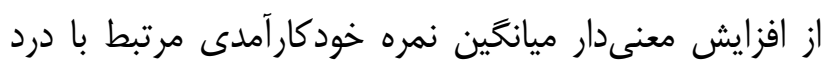

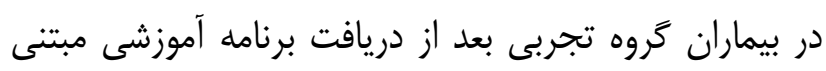

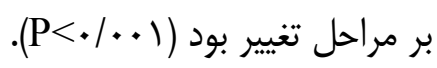
يافتههاى جدول ه ميانخين نمرات مربوط به مراحل تغيير

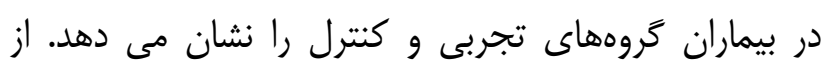




\begin{tabular}{|c|c|c|c|c|}
\hline \multirow{2}{*}{ آزمون تىمستقل } & \multicolumn{2}{|c|}{ كَروه مورد بررسى } & \multirow{2}{*}{ اندازهكيرى مقطع } & \multirow{2}{*}{ متغير مورد } \\
\hline & كنترل & تجربى & & \\
\hline $\mathrm{t}=-\cdot / \Delta T Y$. $\mathrm{P}=\cdot / \Delta \mathrm{H} \Lambda$ & $\mid r / \cdot \varepsilon \pm \mu / / \mathscr{C} D$ & 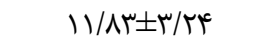 & قبل از مداخله & \\
\hline $\mathrm{t}=\mathrm{r} / q \mathrm{VV}, \mathrm{P}<\cdot 1 \cdots 1$ & $|w /| r \pm x / .$. & $I V / \& \Delta \pm \Delta / \Delta T$ & بعد از مداخله & آكاهى \\
\hline- & $\mathrm{t}=1 / \mathrm{T} \Delta \omega \mathrm{d} \mathrm{P}=\cdot / \mathrm{q} \cdot \mathrm{\mu}$ & $\mathrm{t}=-\Delta / 999, \mathrm{P}<. / \cdots)$ & آَزمون تى زوجى & \\
\hline $\mathrm{t}=-\cdot / q \mu \cdot \mathrm{s}=\cdot / / q q$. & $r m / q q \pm 11 / V$ & $T Y / / \varepsilon \pm 1 \cdot / \mu$ & قبل از مداخله & \\
\hline $\mathrm{t}=\mathrm{V} / \mathrm{r} \Delta \omega \mathrm{d}, \mathrm{P}<\cdot 1 \cdots)$ & rY/UIIr/FG & ${ }^{c} V / \Delta \omega \pm \mid q / T$ & بعد از مداخله & خود كار آمدى \\
\hline- & $\mathrm{t}=-\cdot / \mathrm{V} \cdot \mathrm{V}, \mathrm{P}=\cdot / \mathrm{q} 1 \mathrm{D}$ & $\mathrm{t}=-q / \cdot \wedge \mathrm{r}{ } \mathrm{P}<\cdot / \cdots)$ & آزمون تى زوجى & \\
\hline
\end{tabular}

\begin{tabular}{|c|c|c|c|c|}
\hline P-value قبل و بعد & تعد از مداخله & قبل از مداخله & مرحله تغيير & تخروه \\
\hline \multirow{5}{*}{$\begin{array}{l}Z=-q / 1 \mu . \\
P<\cdot / \cdots 1\end{array}$} & $(\varepsilon / \varepsilon V) r$ & $(58 / 9 V) I f$ & PC (ييشتفكر) PC & \multirow{5}{*}{ كروه تجربى } \\
\hline & $(\mid \xi / \xi q) \Delta$ & • 1 ( 1 (سא/س) & C C C C & \\
\hline & •ו (זس/سז) & $(r \cdot)^{q}$ & (قصد) P & \\
\hline & (I)/ & . & A (عمل) A & \\
\hline & $(\varepsilon / q V) Y$ & $\cdot$ & (نخهراشت) M & \\
\hline \multirow{3}{*}{$Z=-\cdot / \Delta Y \Lambda$} & $(r \cdot)$ Ir & $(\omega \cdot \% \cdot \cdots) 10$ & (ييش تفكر) PC & \\
\hline & $(r \cdot) q$ & •1 (אس/سץ) & Cفكر) C & \\
\hline & $(\tilde{\mu}) \vee$ & $(\mid \varepsilon / \& \varepsilon) \Delta$ & (قصد) P & \\
\hline \multirow[t]{2}{*}{$P=\cdot / \Delta \cdot \Lambda$} & $(g / g V) r$ & • & A (عمل) A & \\
\hline & $\cdot$ & $\cdot$ & (نخهداشت) M & \\
\hline- & $\begin{array}{l}\mathrm{Z}=-\Lambda / \Gamma T \Delta \\
\mathrm{P}<. / \ldots 1\end{array}$ & $\begin{array}{l}\mathrm{Z}=-\cdot / \Delta S T \\
\mathrm{P}=\cdot / \text { \&VT }\end{array}$ & P-value بين دو گروه & \\
\hline
\end{tabular}

"تعداد و درصد بيماران در هر يك از مراحل تغيير كزارش شده است.

شناختى - رفتارى مقابله با دردهاى مزمن است با تمركز بر

عوامل زيستى، روانى و اجتماعى مانند ترس و صدمه از

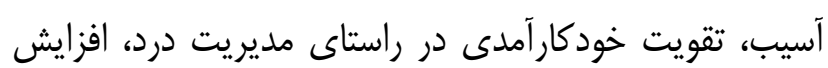

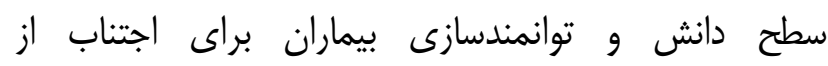

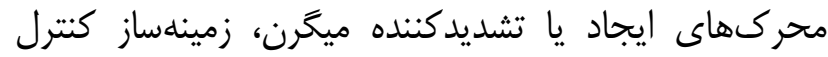

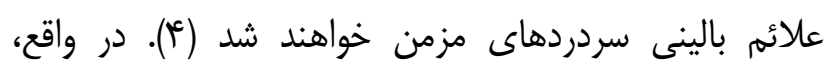

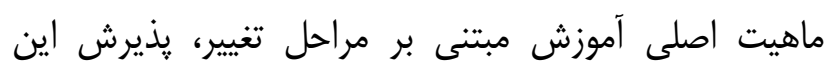
ييشفرض است كه توانايىها و ظرفيتهاى افراد براى مقيت مقابله با تنشهاى جسمانى و روانى متفاوت است و علاوه بر اين، عوامل فردى و محيطى ييشآيند، تشديدكننده و تداومبخش مانش

هدف مطالعه حاضر، تعيين تأثير مداخله آموزشى مبتنى بر مدل مراحل تغيير بر كاربرد مكانيسمهاى غلبه بر درد در بيماران زن مبتلا به ميگررن در شهرستان بندرانزلى بود.

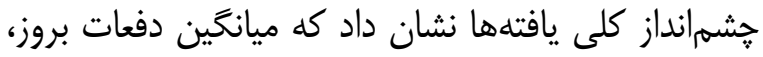
شدت و مدت حملات مرتبط با سردردهاى ميگرنى در بيماران

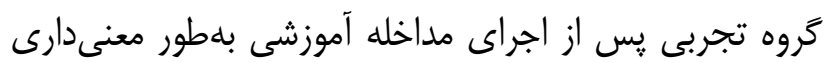

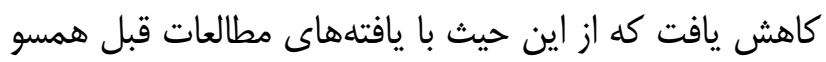

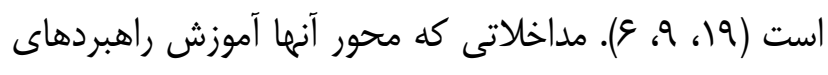




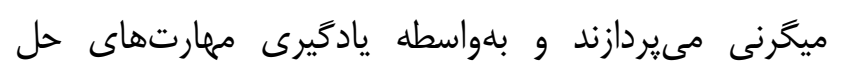

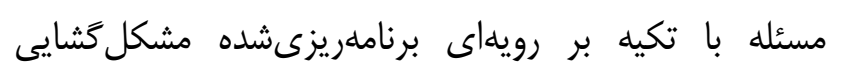

مى كنند (IT) (IT)

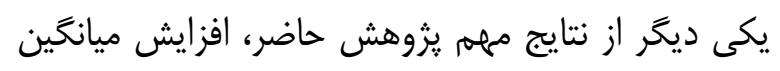

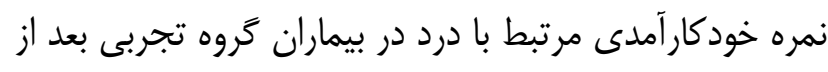

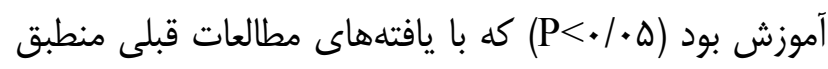

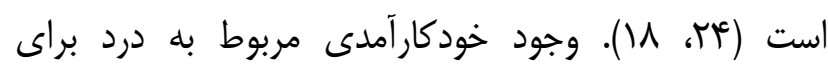

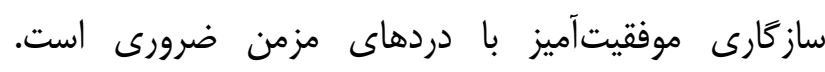

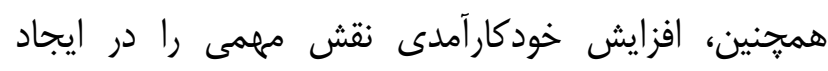

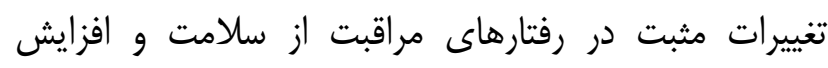

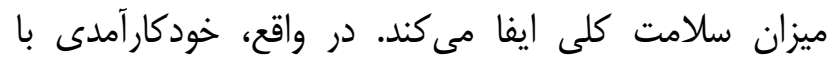

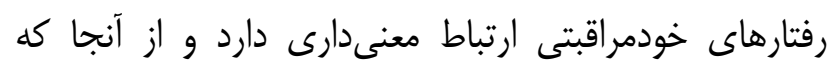

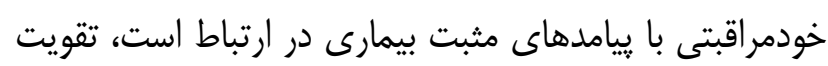

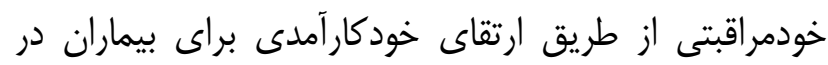

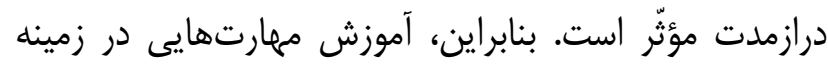

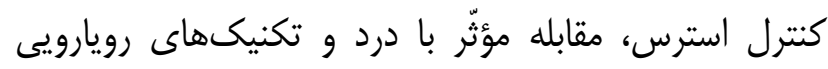

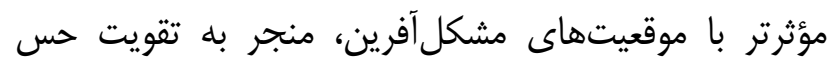

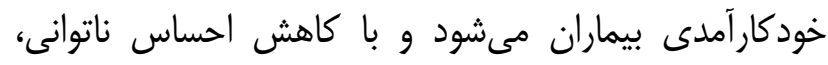

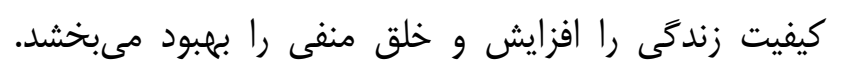

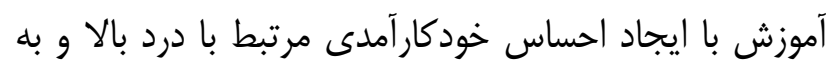

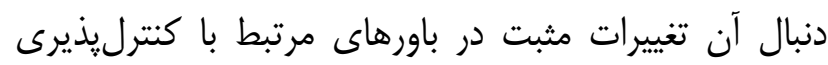

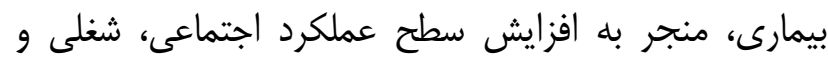

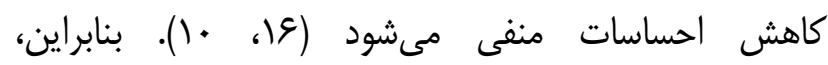

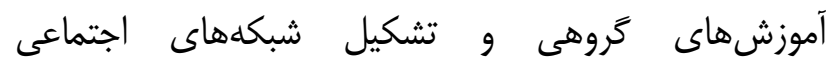

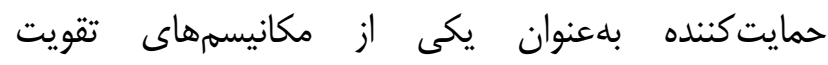

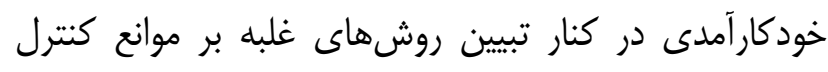

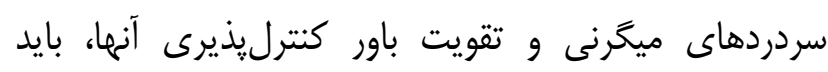

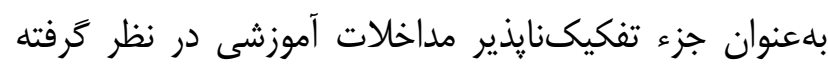

شود.

يافته حائز اهميت ديخر مطالعه حاضر، ارتقاى وضعيت

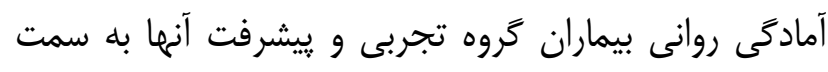

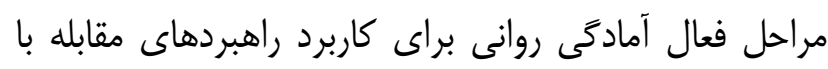

رفتارهاى بهداشتى متفاوت است؛ بر همين اساس، طبقابندى

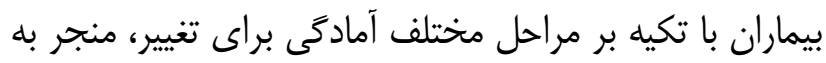

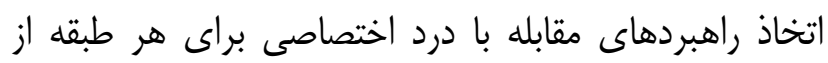

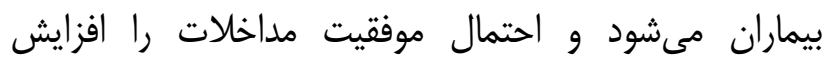

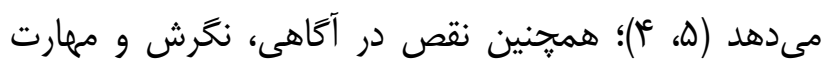

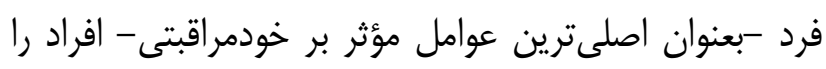

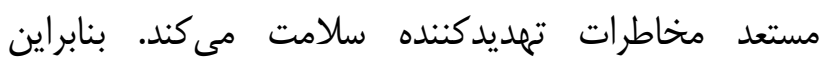

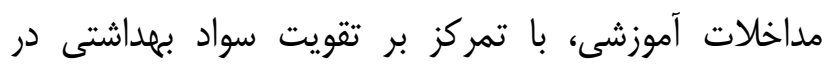

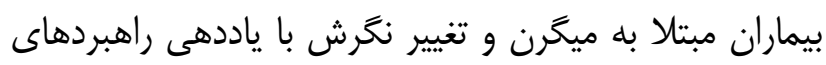

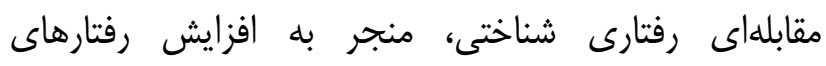

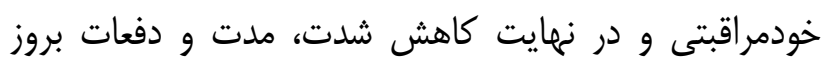
سردردهاى ميكرنى شده است.

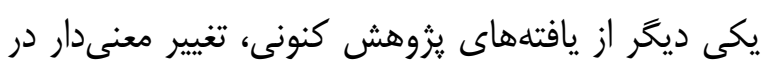

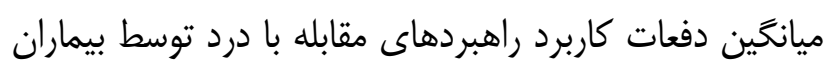

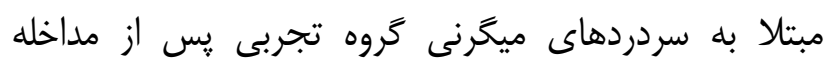

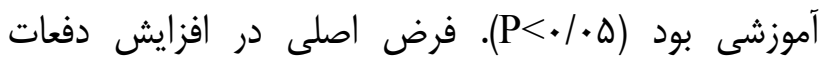

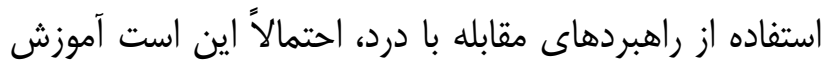

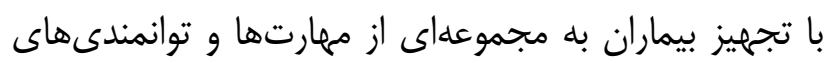

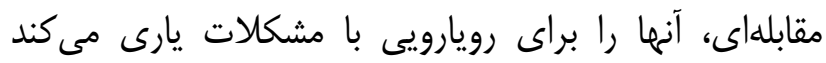

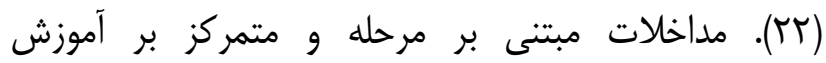

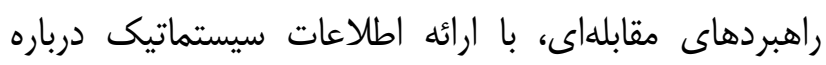

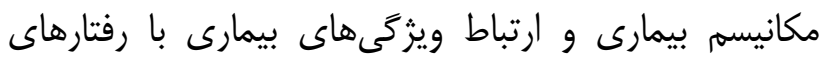

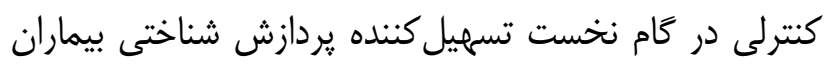

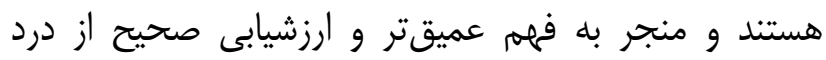

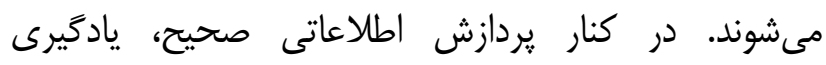

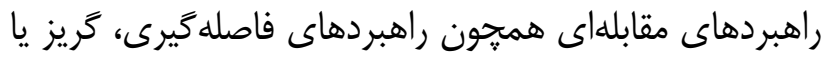

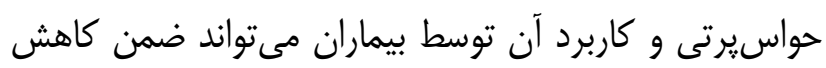

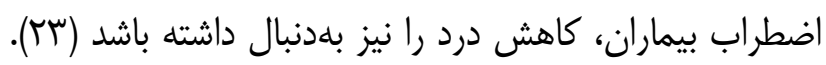

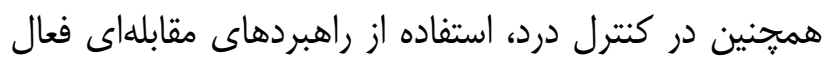

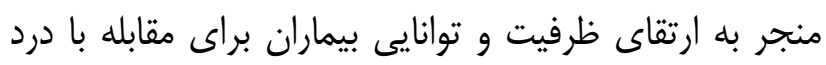

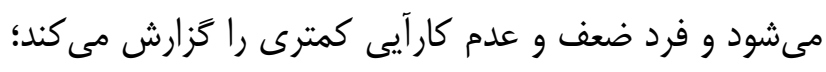

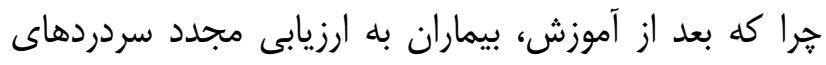


نتيجه، بامنظور تحليل دقيقتر و امكان بهرهيرى از

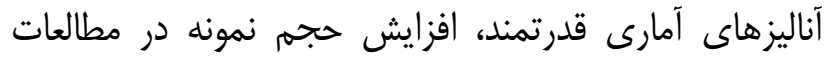

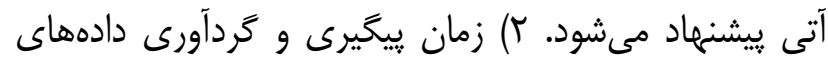

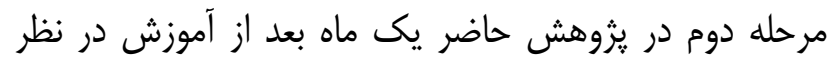

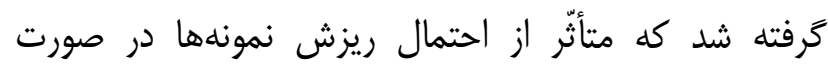

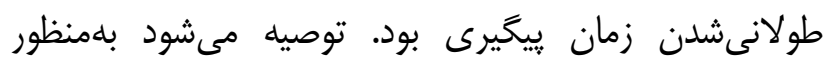

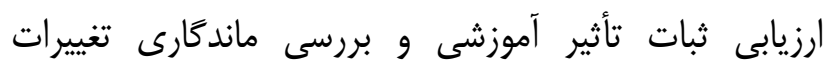

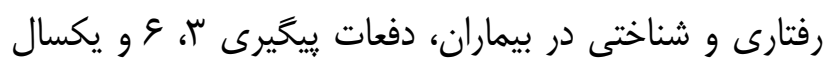

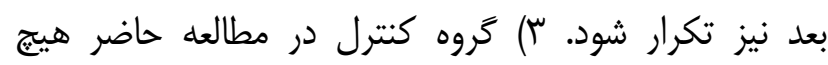

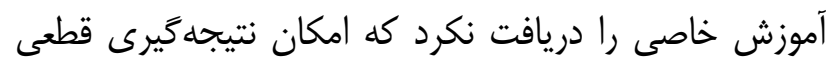

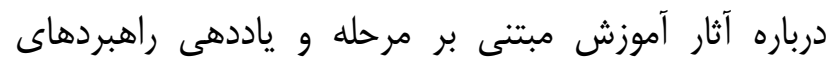

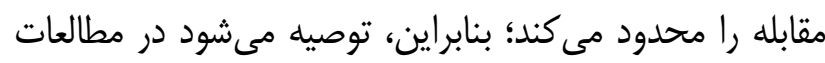

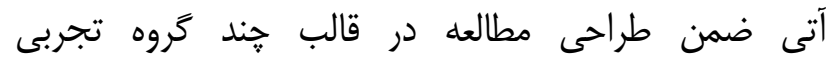

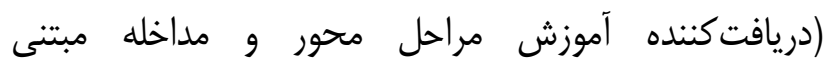

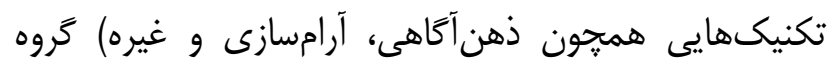

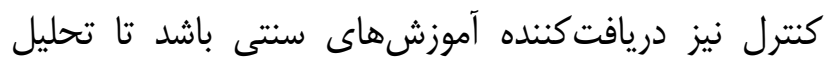
جامعترى درباره كارآمدى آموزش ارئئه شود.

\section{نتيجه كيرى}

يافتهاى مطالعه حاضر نشاندهنده كاهش معنى منىدار

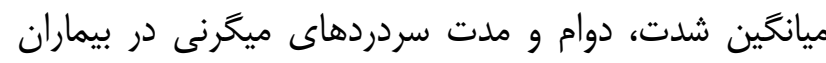

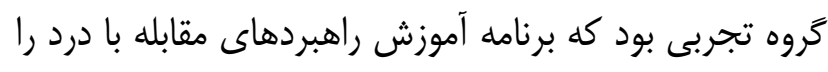

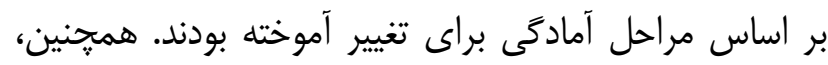

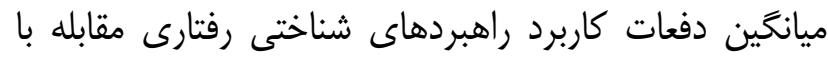

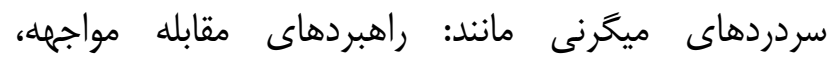

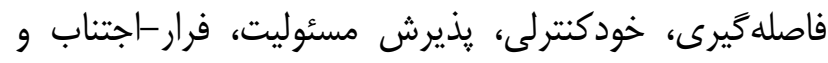

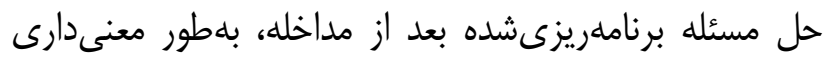
در گروه تجربى افزايش يافت. علاوه بر اين، ميانخين نمره

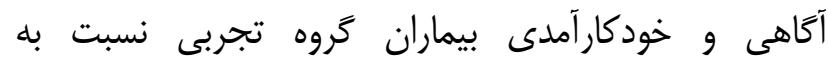

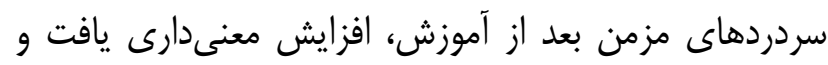

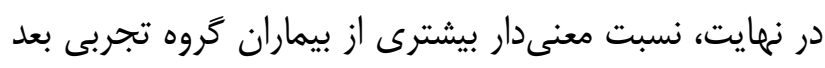

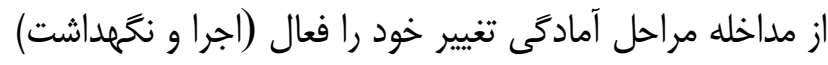

سردردهاى ميخرنى در يزوهش حاضر است كه منطبق با

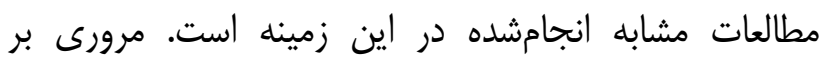

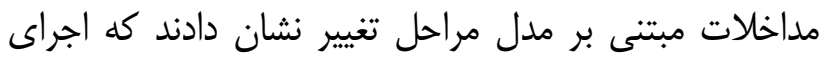
مشاورههاى فردى مبتنى بر مرحله مىتواند درنهايت منجر بـ مبله

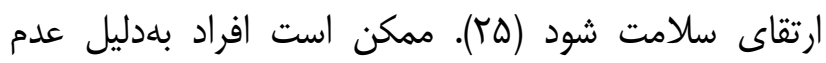

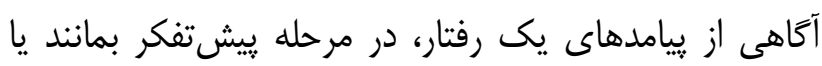

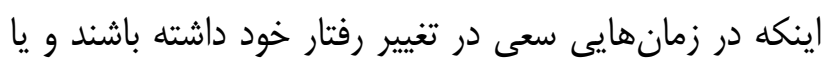

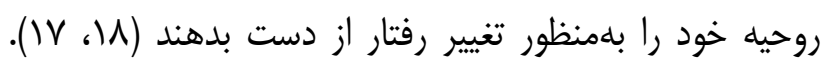

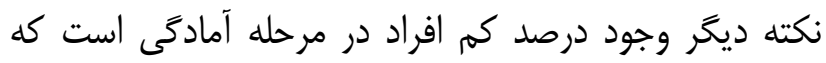

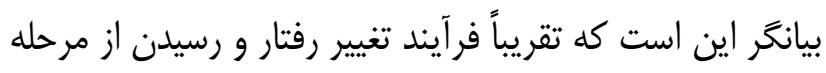

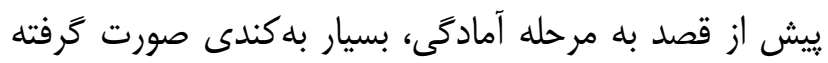

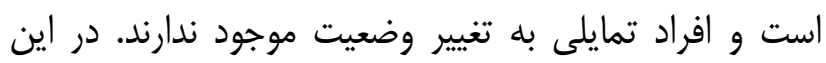
راستا، طراحى ييامهاى بهداشتى و مداخلات مناسب در زمينه

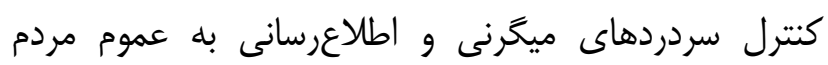

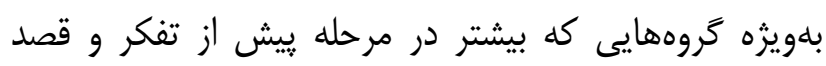
هستند، توصيه مىشود. يكى از نقاط قوت يزوهش حاضر، اضافه كردن مهارت مارتها

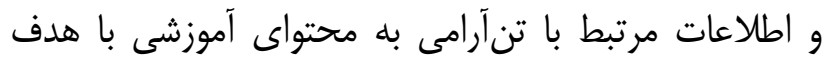

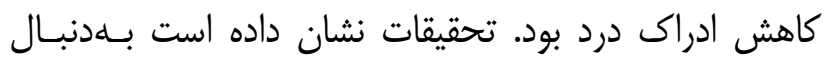

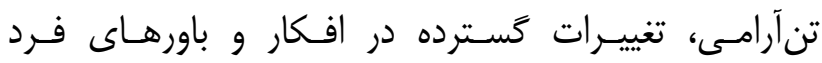

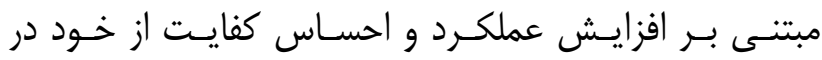

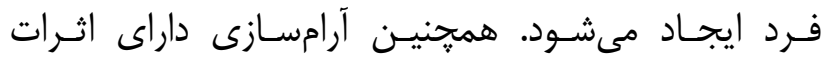

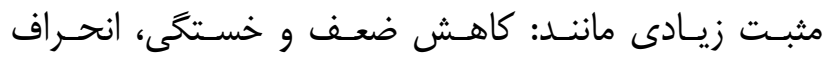

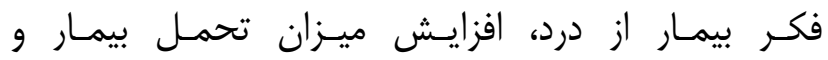

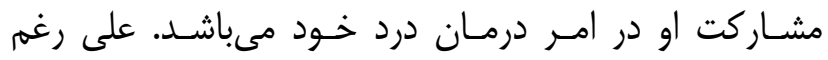
وجود نقاط قوت در يثرهش حاضر مانند: طراحى مداخله

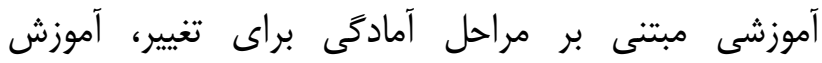

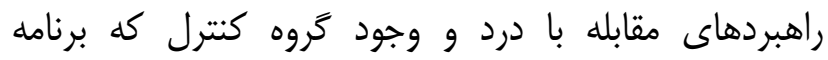
آموزش خاصى را دريافت نكرد، مطالعه كنونى با هُندين

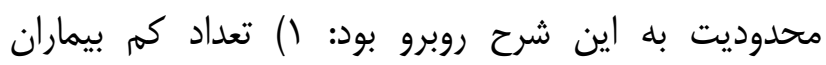

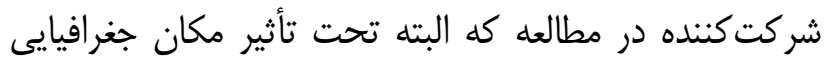

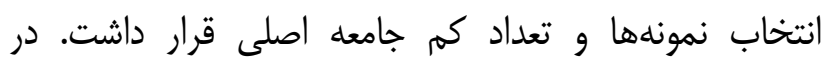




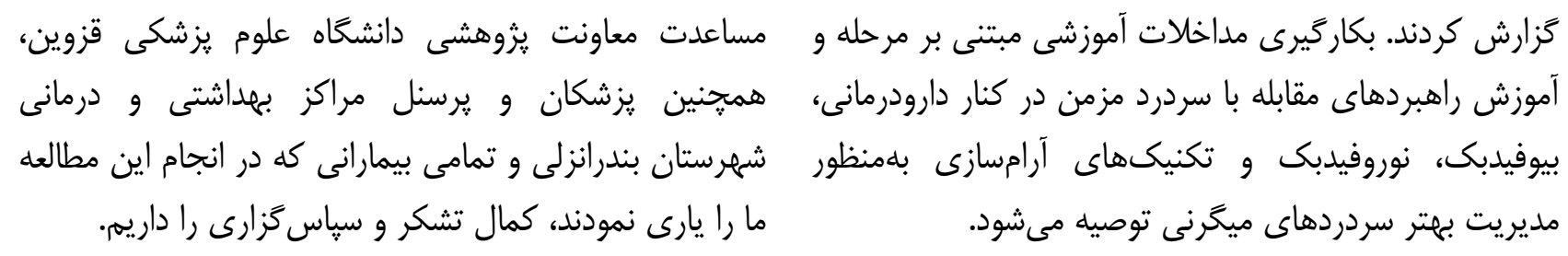

1- Buse DC, Greisman JD, Baigi K, Lipton RB. Migraine Progression: A Systematic Review. Headache. 2019; 59(3): 306-38. doi: 10.1111/head.13459.

2- Dodick DW. A Phase-by-Phase Review of Migraine Pathophysiology. Headache. 2018; 58 Suppl 1: 4-16. doi: 10.1111/head.13300.

3- Baksa D, Gonda X, Juhasz G. Why are migraineurs more depressed? A review of the factors contributing to the comorbidity ofmigraine and depression. Neuropsychopharmacol Hung. 2017; 19(1): 37-44.

4- Farhadi Z, Alidoost S, Behzadifar M, Mohammadibakhsh R, Khodadadi N, Sepehrian R, et al. The Prevalence of Migraine in Iran: A Systematic Review and Meta-Analysis. Iran Red Crescent Med J. 2016; 18(10): e40061. doi: $10.5812 /$ ircmj.40061

5- GBD 2016 Headache Collaborators. Global, regional, and national burden of migraine and tension-type headache, 1990-2016: a systematic analysis for the Global Burden of Disease Study 2016. Lancet Neurol. 2018; 17(11): 954-76. doi: 10.1016/S1474-4422(18)30322-3.

6- Naprienko MV, Smekalkina LV, Safonov MI, Filatova EG, Latysheva NV, Ekusheva EV, et al. [Realworld migraine burden: clinical and economic aspects]. Zh Nevrol Psikhiatr Im S S Korsakova. 2019; 119(1): 3137. doi: 10.17116/jnevro201911901131. [Russian]

7- Burch R. Migraine and Tension-Type Headache: Diagnosis and Treatment. Med Clin North Am. 2019; 103(2): 21533. doi: 10.1016/j.mcna.2018.10.003.

8- Martin PR, Aiello R, Gilson K, Meadows G, Milgrom J, Reece J. Cognitive behavior therapy for comorbid migraine and/or tension-type headache and major depressive disorder: An exploratory randomized controlled trial. Behav Res Ther. 2015; 73: 8-18. doi: 10.1016/j.brat.2015.07.005.

9- Ng QX, Venkatanarayanan N, Kumar L. A Systematic Review and Meta-Analysis of the Efficacy of Cognitive Behavioral Therapy for the Management of Pediatric Migraine. Headache. 2017; 57(3): 349-62. doi: 10.1111/head.13016.

10- Costa DSJ, Asghari A, Nicholas MK. Item response theory analysis of the Pain Self-Efficacy Questionnaire. Scand J Pain. 2017; 14: 113-7. doi: 10.1016/j.sjpain.2016.08.001.

11- Paroli M, Bernini O, De Carolis G, Tollapi L, Bondi F, Martini A, et al. Are Multidimensional Pain Inventory Coping Strategy Profiles Associated with Long-Term Spinal Cord Stimulation Effectiveness? Pain Med. 2018; 19(5): 1023-32. doi: 10.1093/pm/pnx106.

12- Munday I, Kneebone I, Newton-John T. The language of chronic pain. Disabil Rehabil. 2019: 1-8. doi: 10.1080/09638288.2019.1624842.

13- Larijani R, Besharat MA. Perfectionism and coping styles with stress. Procedia Soc Behav Sci. 2010; 5: 623-7. doi: 10.1016/j.sbspro.2010.07.154 
14- Soleimani E, Habibi Asgarabad M, Basharpour S, Shikheslami A, Nooripour Liavali R. Effectiveness of SelfControl Training on Quality of Life Dimensions in Migraine Patients. J Arak Uni Med Sci. 2016; 19(3): 27-7. [Persian]

15- Pecukonis EV. Physical self-efficacy and alexithymia in women with chronic intractable back pain. Pain Manag Nurs. 2009; 10(3): 116-23. doi: 10.1016/j.pmn.2008.11.001.

16- Prochaska JO, Butterworth S, Redding CA, Burden V, Perrin N, Leo M, et al. Initial efficacy of MI, TTM tailoring and HRI's with multiple behaviors for employee health promotion. Prev Med. 2008; 46(3): 226-31. DOI: 10.1016/j.ypmed.2007.11.007

17- Lee JY, Park HA, Min YH. Transtheoretical model-based nursing intervention on lifestyle change: a review focused on intervention delivery methods. Asian Nurs Res (Korean Soc Nurs Sci). 2015; 9(2): 158-67. doi: 10.1016/j.anr.2015.05.001.

18- Tang SM, Chen CH, Chen JY. Applying the transtheoretical model to tobacco prevention education in adolescence: a literature review. Hu Li Za Zhi. 2009; 56(2): 81-8. [Chinese]

19- Hamedanizadeh F, Mahmoudzadeh Zarandi F, Ebadi A, Asad Zandi M, Kachouei H. Effectiveness of implementation of orem self-care program on headache indices in Migraineur. Kowsar Med J. 2010; 15(3): $155-61$. [Persian]

20- Billings AG, Moos RH. The role of coping responses and social resources in attenuating the stress of life events. J Behav Med. 1981; 4(2): 139-57.

21- Evans JR, Mano KJ, Guite JW, Weisman SJ, Hainsworth KR. Psychometric properties of the pain stages of change questionnaire: new insights on the measurement of readiness to change in adolescents, mothers, and fathers. $\mathrm{J}$ Pain. 2015; 16(7): 645-56. doi: 10.1016/j.jpain.2015.03.012.

22- Janevic MR, Shute V, Connell CM, Piette JD, Goesling J, Fynke J. The Role of Pets in Supporting CognitiveBehavioral Chronic Pain Self-Management: Perspectives of Older Adults. J Appl Gerontol. 2019: 733464819856270. doi: $10.1177 / 0733464819856270$.

23- Havaiy A, Kazemi H, Habibollahi A, Izadikhah Z. The Effect of Emotion Regulation on the Amount of Tension Tolerance and Emotion Regulation Difficulties in Women with Tension-type Headaches. J Shahid Sadoughi Univ Med Sci. 2017; 24(10): 840-51. [Persian]

24- Peck KR, Smitherman TA. Mediator Variables in Headache Research: Methodological Critique and Exemplar Using Self-Efficacy as a Mediator of the Relationship Between Headache Severity and Disability. Headache. 2015; 55(8): 1102-11. doi: 10.1111/head.12633.

25- Lee JY, Park HA, Min YH. Transtheoretical Model-based Nursing Intervention on Lifestyle Change: A Review Focused on Intervention Delivery Methods. Asian Nurs Res (Korean Soc Nurs Sci). 2015; 9(2): $158-67$. 